\title{
Anatomia foliar como subsídio à taxonomia de espécies do Complexo Briza L. (Poaceae: Pooideae: Poeae) ${ }^{1}$
}

\author{
Carla Maria Garlet de Pelegrinn ${ }^{2,3}$, Hilda Maria Longhi-Wagner ${ }^{2}$ e Paulo Luiz de Oliveira ${ }^{2}$
}

Recebido em 29/05/2008. Aceito em 6/10/2008

RESUMO - (Anatomia foliar como subsídio à taxonomia de espécies do Complexo Briza L. (Poaceae: Pooideae: Poeae)). O objetivo deste trabalho foi verificar a importância da anatomia foliar, visando a fornecer subsídios para a taxonomia do Complexo Briza, cuja circunscrição vem sendo objeto de discussão. Porções medianas da segunda folha abaixo da inflorescência de 21 táxons do Complexo Briza e um de Erianthecium Parodi foram coletadas, fixadas e processadas de acordo com a metodologia usual em microscopia óptica. Todas as espécies estudadas apresentam padrão anatômico festucóide, característico de gramíneas $\mathrm{C}_{3}$. Os resultados mostram que os caracteres da face abaxial da epiderme relativos à presença/ausência de células suberosas e à forma dos corpos silicosos são úteis para compreender as relações taxonômicas no Complexo Briza, distinguindo as espécies eurasiáticas das americanas. Da mesma forma, alguns caracteres da secção transversal da lâmina foliar como forma da lâmina, quantidade de esclerênquima e estrutura do mesofilo. Por outro lado, com relação às espécies americanas do Complexo Briza, os três agrupamentos aqui obtidos não correspondem a nenhuma proposta anterior de categorias taxonômicas genéricas ou infragenéricas.

Palavras-chave: anatomia foliar, Complexo Briza, Erianthecium bulbosum, Gramineae, Poeae

ABSTRACT - (Leaf anatomy as a taxonomic tool for Briza Complex species (Poaceae: Pooideae: Poeae)). The aim of this study was to analyze leaf anatomy of selected taxa of the Briza Complex and also of a related genus, Erianthecium Parodi, to provide data for the taxonomy of the Complex, whose circumscription is being discussed. Middle portions of the second leaf below the inflorescence of 21 taxa of the Briza Complex and of Erianthecium bulbosum were collected, fixed and processed according to conventional methodology for light microscopy. All species present anatomical patterns typical of festucoid and C3 grasses. The results suggest that the characters of the abaxial surface of the epidermis such as presence/absence of cork cells and shape of silica bodies are useful for understanding the taxonomic relationships within the Briza Complex, distinguishing Eurasiatic species from American species. The same applies to several characters of the leaf blade in cross-section, e.g. blade shape, amount of sclerenchyma and structure of the mesophyll. On the other hand, in the American species of the "Briza Complex", the three groups obtained here do not agree with any previous proposal of generic or infrageneric taxonomic categories.

Key words: Briza Complex, Erianthecium bulbosum, Gramineae, leaf anatomy, Poeae

\section{Introdução}

O gênero Briza L. (Poaceae, tribo Poeae) foi descrito com três espécies européias: Briza maxima L., B. media L. e $B$. minor L. Posteriormente, foram descritas B. humilis M. Bieb., da Ucrânia e espécies americanas de Briza ou em gêneros relacionados como Calotheca Desv., Chascolytrum Desv., Poidium Nees, Rhombolytrum Link, Gymnachne Parodi, Lombardochloa Roseng. \& Arrill. e Microbriza Parodi. Autores posteriores passaram a tratar Briza e os gêneros relacionados com diferentes circunscrições, aceitando Briza sensuu lato, com um número variável de subgêneros ou seções (Parodi 1920; Longhi-Wagner 1987), ou aceitando Briza sensu stricto, considerando parte dos subgêneros ou seções americanas como gêneros independentes (Matthei 1975; Nicora \& Rúgolo de Agrasar 1981; Essi 2007). Devido às divergências na circunscrição genérica, o grupo passou a ser denominado de Complexo Briza (Matthei 1975; Nicora \& Rúgolo de Agrasar 1981; Longhi-Wagner 1987; Bayón 1998).

Briza s. l. inclui quatro espécies da Eurásia e 16 a 22 espécies nativas de regiões temperadas e subtropicais especialmente da América do Sul, todas perenes (Longhi-Wagner 1987; Essi 2007), constituindo-se em importantes componentes das pastagens naturais na época de inverno, período crítico para a pecuária. A maior diversidade específica do ramo americano está no sul do Brasil, onde também ocorrem as espécies adventícias anuais, B. maxima e B. minor.

Matthei (1975) aceitou o gênero Briza s. str. e distribuiu as espécies americanas entre os gêneros Calotheca, Chascolytrum e Poidium, excluindo Briza bidentata Roseng., Arrill. \& Izag. e B. brasiliensis (Nees ex Steud.) Ekman do Complexo, com base na morfologia externa, embora tenha fornecido alguns dados de citogenética, anatomia foliar e embrião.

Essi et al. (2008) consideraram pertencentes ao gênero Briza apenas as espécies eurasiáticas, concordando com Matthei (1975), mas propõem a inclusão das espécies americanas em um só gênero, Chascolytrum. No mesmo trabalho, o gênero monoespecífico Erianthecium Parodi, nunca considerado membro do Complexo, aparece incluído no clado das espécies americanas, em Chascolytrum.

O gênero Briza s. l. é morfologicamente heterogêneo, o que em parte explica as diferentes circunscrições até hoje a ele propostas. A variação encontrada se refere especialmente às formas do lema e da pálea, às dimensões das espiguetas e à coloração do lema (Longhi-Wagner 1987). Além do problema da circunscrição genérica do Complexo, algumas espécies possuem variações morfológicas infraespecíficas que suscitam dúvidas sobre a sua circunscrição. Este é o caso de B. subaristata Lam., para a qual foi proposta a variedade interrupta (Rosengurtt et al. 1968)

\footnotetext{
Parte da Dissertação de Mestrado da primeira Autora

2 Programa de Pós-Graduação em Botânica, Universidade Federal do Rio Grande do Sul, Departamento de Botânica, Porto Alegre, RS, Brasil

3 Autor para correspondência: carla_pelegrin@yahoo.com.br
} 
Considerendo ainda as variações morfológicas em Briza, Longhi-Wagner (1987) referiu que os indivíduos de Briza calotheca (Trin.) Hack. que ocorrem em campos mais secos apresentam menor porte e lâminas foliares mais estreitas e rígidas do que os de ambientes alagados.

Na taxonomia das Poaceae, a anatomia foliar foi utilizada pela primeira vez por Duval-Jouve (1875). Desde então, caracteres anatômicos foliares vêm sendo utilizados na definição de subfamílias, combinados com dados morfológicos (Prat 1936; Clayton \& Renvoize 1986) e, mais recentemente, com dados moleculares (GPWG 2001). A análise da anatomia foliar também tem sido utilizada em outros níveis taxonômicos fornecendo vários caracteres constantes e diagnósticos. ( Metcalfe 1960; Ellis 1976; 1979; 1987; López \& Devesa 1991; Torres \& Engleman 1995; Sánchez \& Koch 1998; Vieira et al. 2002; Kesler et al. 2003, Silva \& Alquini 2003; Alvarez et al. 2005; Ma et al. 2005; Finot et al. 2006; Guevara \& Ramia 2007; Kharazian 2007).

Estudos anatômicos em Briza s. l. foram realizados, principalmente, com espécies eurasiáticas (Schwendener 1890; Lohauss 1905). Segundo Prat (1936) e Decker (1964), os caracteres do gênero são do tipo festucóide. Carolin et al. (1973) analisaram as células do mesofilo e da bainha vascular parenquimática de $B$. subaristata, concluindo que esta se enquadra no tipo poóide de anatomia foliar, que corresponde ao tipo festucóide

Pela importância do estudo da anatomia foliar como critério taxonômico em Poaceae, e pelos problemas de circunscrição genérica e infra-específica no Complexo Briza realizou-se o presente estudo, visando a: 1) analisar a anatomia foliar de táxons selecionados do Complexo Briza e uma espécie relacionada (Erianthecium bulbosum) como subsídios à taxonomia do Complexo e para a análise de sua circunscrição; 2) comparar a anatomia foliar das espécies eurasiáticas com a das espécies americanas do Complexo Briza; 3) verificar características anatômicas foliares utilizáveis na delimitação de alguns táxons morfologicamente afins, ou com grande variação morfológica e na proposição de táxons infra-específicos.

\section{Material e métodos}

O material botânico foi coletado em formações campestres dos Estados do Rio Grande do Sul e Santa Catarina, na Região Sul do Brasil. A maior parte do material foi coletada em campos secos, com exceção de Briza juergensii, coletada em turfeiras dos campos de altitude do nordeste do Rio Grande do Sul, e de B. calotheca, da qual foram coletados materiais tanto em campos secos quanto em turfeiras. Espécimes não ocorrentes no Brasil foram obtidos nos herbários das Universidades de Córdoba (Argentina) e Bogotá (Bolívia), do Instituto de Botánica Darwinion (Argentina) e do Royal Botanic Gardens (Kew, Inglaterra). Erianthecium bulbosum (tribo Poeae), foi usada para comparação, por estar incluída no clado Chascolytrum, Essi et al. (2008). Os morfotipos de B. juergensii Hack. e B. lamarckiana Nees foram tratados como $B$. aff. juergensii e $B$. aff. lamarckiana. Da mesma forma, um morfotipo de B. paleapilifera Parodi, citado por Essi (2007) para a Bolívia, foi incluído como B. aff. paleapilifera. Os exemplares-testemunho estão, na maior parte, depositados no herbário ICN, e materiais dos herbários BAA, LPB e K (acrônimos conforme Holmgren \& Holmgren 1998) também foram utilizados (Tab.1).
Tabela 1. Lista de material utilizado para a análise da anatomia foliar. *Eemplares de herbário reidratados. + gênero Poidium Nees; ++ gênero Chascolytrum Desv.; +++ gênero Briza L.; - excluídas do Complexo (Matthei 1975).

\begin{tabular}{|c|c|c|}
\hline Acrônimos & Táxons & Amostras analisadas \\
\hline $\mathrm{AMBI}^{+}$ & Briza ambigua Hack. & $\begin{array}{l}\text { L. Essi et al. } 190(\mathrm{ICN}) \\
\text { L. Essi et al. } 192(\mathrm{ICN}) \\
\text { A. Zanin } \text { et al. } 1132^{*}(\mathrm{ICN})\end{array}$ \\
\hline $\mathrm{BIDE}^{-}$ & $\begin{array}{l}\text { B. bidentata Roseng. } \\
\text { Arrill. \& Izag. }\end{array}$ & $\begin{array}{l}\text { L. Essi et al. } 50 \text { (ICN) } \\
\text { L. Essi } \text { et al. } 51 \text { (ICN) } \\
\text { C.M.G. de Pelegrin s.n. (ICN 148981) }\end{array}$ \\
\hline BRAS & $\begin{array}{l}\text { B. brasiliensis (Nees ex } \\
\text { Steud.) Ekman }\end{array}$ & R.M. 357* (ICN 149151) \\
\hline CAL1 ${ }^{+}$ & $\begin{array}{l}\text { B. calotheca (Trin.) Hack. } \\
\text { (banhado) }\end{array}$ & C.M.G. de Pelegrin s.n. (ICN 148979) \\
\hline $\mathrm{CAL}^{2}{ }^{+}$ & $\begin{array}{l}\text { B. calotheca (Trin.) Hack. } \\
\text { (seco) }\end{array}$ & $\begin{array}{l}\text { C.M.G. de Pelegrin s.n.(ICN 148980) } \\
\text { H. Longhi-Wagner } 9872 \text { (ICN) } \\
\text { H. Longhi-Wagner } 3995^{*} \text { (ICN) } \\
\text { H. Longhi-Wagner } 9877 \text { (ICN) } \\
\text { P.G. Windisch et al. } 9635^{*} \text { (ICN) }\end{array}$ \\
\hline HUMI ${ }^{+++}$ & B.a humilis M. Bieb. & Davis \& Hedge 2777 \\
\hline JUE1 + & B. juergensii Hack. & $\begin{array}{l}\text { A. Zanin et al. } 975^{*}(\mathrm{ICN}) \\
\text { C.M.G. de Pelegrin s.n. (ICN148983) } \\
\text { L.F. Lima } 331^{*} \text { (ICN) }\end{array}$ \\
\hline JUE2 + & $\begin{array}{l}\text { B. aff. juergensii } \\
\text { (lemas estreitos) }\end{array}$ & $\begin{array}{l}\text { H.Longhi-Wagner } 10235 \text { (ICN) } \\
\text { L. Essi et al. } 122^{*}(\mathrm{ICN}) \\
\text { H. Longhi-Wagner } 8009^{*}\end{array}$ \\
\hline 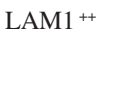 & B. lamarckiana Nees & $\begin{array}{l}\text { C.M.G. de Pelegrin s.n. (ICN 148985) } \\
\text { H. Longhi-Wagner } 10203 \text { (ICN) } \\
\text { H. Longhi-Wagner } 9871 \text { (ICN) }\end{array}$ \\
\hline $\mathrm{LAM}^{++}$ & $\begin{array}{l}\text { B. aff. lamarckiana } \\
\text { (lema sem cor castanha } \\
\text { no dorso) }\end{array}$ & $\begin{array}{l}\text { L. Passaglia } 13^{*}(\mathrm{ICN}) \\
\text { A.M. Sacchet } 60^{*}(\mathrm{ICN}) \\
\text { A.M. Sacchet } 124^{*}(\mathrm{ICN})\end{array}$ \\
\hline $\mathrm{MONA}^{+}$ & B. monandra (Hack.) Pilg. & $\begin{array}{l}\text { J. Valls et al. 11499* (ICN) } \\
\text { L. Essi } 239(\mathrm{ICN}) \\
\text { I. Boldrini } 1356^{*}(\mathrm{ICN})\end{array}$ \\
\hline MAXI $^{+++}$ & B. maxima $\mathrm{L}$. & $\begin{array}{l}\text { M.T. Sampaio s.n. (ICN 46809)* } \\
\text { M.T. Sampaio s.n. (ICN 46807)* } \\
\text { L. Essi } \text { et al. } 45 \text { (ICN) }\end{array}$ \\
\hline MEDI $^{+++}$ & B. media $\mathrm{L}$. & $\begin{array}{l}\text { M.L. Porto } 2785^{*}(\mathrm{ICN}) \\
\text { M.L. Porto } 2795^{*}(\mathrm{ICN}) \\
\text { L. Essi } 256(\mathrm{ICN})\end{array}$ \\
\hline $\mathrm{MINO}^{+++}$ & B. minor $\mathrm{L}$. & $\begin{array}{l}\text { H. Longhi-Wagner } 10222 \text { (ICN) } \\
\text { H. Longhi-Wagner } 10193 \text { (ICN) } \\
\text { C.M.G. de Pelegrin s.n. (ICN } 148975\end{array}$ \\
\hline PAL1 ${ }^{++}$ & B. paleapilifera Parodi & $\begin{array}{l}\text { A. Anton } 359^{*}(\mathrm{ICN}) \\
\text { F. Zuloaga s.n.* (BAA) }\end{array}$ \\
\hline PAL2 ${ }^{++}$ & $B$. aff. paleapilifera & $\begin{array}{l}\text { J.R.I. Wood s.n.* (LPB 10768) } \\
\text { J.R.I. Wood s.n.* (LPB 10841) }\end{array}$ \\
\hline $\mathrm{POAE}^{+}$ & $\begin{array}{l}\text { B. poaemorpha (J. Presl) } \\
\text { Henr. }\end{array}$ & $\begin{array}{l}\text { H. Longhi-Wagner } 10220 \text { (ICN) } \\
\text { H. Longhi-Wagner } 10224 \text { (ICN) } \\
\text { C.M.G. de Pelegrin s.n. (ICN 148976) }\end{array}$ \\
\hline RUFA $^{+}$ & B. rufa (J. Presl) Steud. & $\begin{array}{l}\text { H. Longhi-Wagner } 10218 \text { (ICN) } \\
\text { H. Longhi-Wagner } 10185 \text { (ICN) } \\
\text { H. Longhi-Wagner } 10202 \text { (ICN) }\end{array}$ \\
\hline SUB1 + & $\begin{array}{l}\text { B. subaristata var. interrupta } \\
\text { (Hack.) Roseng. }\end{array}$ & H. Longhi-Wagner 10194 (ICN) \\
\hline & & $\begin{array}{l}\text { H. Longhi-Wagner } 10186 \text { (ICN) } \\
\text { H. Longhi-Wagner } 10188 \text { (ICN) }\end{array}$ \\
\hline SUB2 + & $\begin{array}{l}\text { B. subaristata Lam. } \\
\text { var. subaristata }\end{array}$ & $\begin{array}{l}\text { H. Longhi-Wagner } 9847 \text { (ICN) } \\
\text { A.Guglieri \& F.J.M. Caporal } 428^{*} \\
\text { (ICN) }\end{array}$ \\
\hline $\mathrm{UNIO}^{+}$ & B. uniolae (Nees) Steud. & $\begin{array}{l}\text { H. Longhi-Wagner } 9875 \text { (ICN) } \\
\text { H. Longhi-Wagner } 10221 \text { (ICN) } \\
\text { C.M.G. de Pelegrin s.n. (ICN 148973) }\end{array}$ \\
\hline BULB & $\begin{array}{l}\text { Erianthecium bulbosum } \\
\text { Parodi }\end{array}$ & $\begin{array}{l}\text { L. Essi et al. } 60 \text { (ICN) } \\
\text { A. Guglieri et al. s.n.* (ICN 143517) } \\
\text { H. Longhi-Wagner \& L. Essi 9292* } \\
\text { (ICN) }\end{array}$ \\
\hline
\end{tabular}


Para testar caracteres utilizáveis na avaliação da circunscrição do gênero Briza, se sensu lato ou sensu stricto, todas as espécies estão sendo tratadas como Briza, seguindo Longhi-Wagner (1987), exceto Erianthecium bulbosum.

Utilizaram-se lâminas foliares totalmente expandidas de 21 táxons do Complexo Briza e um do gênero relacionado Erianthecium. Porções da região mediana da segunda folha abaixo da inflorescência foram fixadas em FAA 70 (Johansen 1940) para extrair a epiderme. Para a secção transversal, as lâminas foliares foram fixadas com glutaraldeído $1 \%$ e formaldeído 4\% (MacDowell \& Trump 1976) em tampão fosfato de sódio, $0,1 \mathrm{M}$ e pH 7,2. Para espécies não ocorrentes no Brasil, foi utilizado material herborizado reidratado em série etílica decrescente $\left(96^{\circ}-50^{\circ}\right)$ e, após, fixado em FAA 70 .

A face abaxial da epiderme (vista frontal) foi preparada segundo Metcalfe (1960) e as amostras coradas com Safranina 1\% e montadas em gelatina glicerinada. Para extrair a face abaxial da epiderme de Briza brasiliensis, na qual não foi possível utilizar o método de Metcalfe (1960), foi feita dissociação com ácido lático (Aiken et al. 1984, adaptado).

Foi realizado teste histoquímico com Sudan III (Sass 1951) para testar a presença de suberina nas paredes das células curtas da face abaxial da epiderme.

$\mathrm{Na}$ análise da secção transversal das lâminas foliares, as amostras foram desidratadas em série etílica, incluídas em hidroxietilmetacrilato (Gerrits \& Smid 1983), seccionadas com $5 \mu \mathrm{m}$ de espessura em micrótomo de rotação Zeiss Mikron, equipado com navalha de vidro de $8 \mathrm{~mm}$ de espessura. As seç̧ões foram coradas com Azul de Toluidina 0,05\% em pH 4,4 (Feder \& O'Brien 1968). As lâminas foram observadas com microscópio óptico Olympus BX 41 e fotografadas com câmara fotográfica acoplada ao microscópio. A terminologia utilizada baseou-se em Ellis (1976; 1979), com exceção da nomenclatura para a forma das células subsidiárias estomáticas. Para corpos silicosos utilizou-se Madella et al. (2005).

Os caracteres com seus estados são referidos na Tab. 4. A partir destes, foi confeccionada uma matriz básica de dados com 22 unidades taxonômicas $\times 17$ caracteres (Tab. 5). A semelhança entre os caracteres dos 22 táxons foi analisada pelo método de Coeficiente de Combinação Simples ("Simple Matching Coefficient"), com posterior análise de agrupamento por média não ponderada - UPGMA (Rohlf 2000). Para verificar a estabilidade dos agrupamentos, foram realizadas 1000 aleatorizações "bootstrap" e foi gerada a curva de evolução das probabilidades estimadas, com um intervalo de confiança de $90 \%$. As análises foram realizadas no programa Multiv (Pillar 2001). A aceitação dos quatro grupos, a partir do fenograma obtido, baseou-se no intervalo de confiança de 90\% (Pillar 1999).

\section{Resultados e discussão}

Os táxons analisados possuem anatomia foliar típica de gramíneas festucóides (Ellis 1987), com padrão anatômico de gramíneas $\mathrm{C}_{3}$ como característico da subfamília Pooideae (Brown 1958). Um detalhamento comparativo das características anatômicas selecionadas das espécies analisadas encontra-se nas Tab. 2, 3.

Vista frontal da epiderme - As células epidérmicas dispõem-se em fileiras longitudinais e estão distribuídas em zonas costais (sobre os feixes vasculares) e intercostais (entre eles), como é característico da família Poaceae (Fig. 1). A epiderme apresenta células longas intercaladas por células curtas. Estas últimas podem ser suberosas ou silicificadas e estão juntas na maioria das espécies analisadas (Fig. 3). As células curtas ocorrem apenas na região costal nas espécies eurasiáticas de Briza (Fig. 5) e também nas americanas B. monandra, B. poaemorpha, B. rufa e Erianthecium bulbosum, enquanto nas demais espécies americanas ocorrem nas regiões costal e intercostal (Fig. 6). Células curtas apenas na região costal também foram constatadas em espécies de Lolium L. e Festuca L. (Badoux 1971), assim como em Hordeum vulgare L. (Wenzel et al. 1997).

As células silicificadas, em Poaceae, são células especializadas da epiderme que acumulam sílica, as quais contêm corpos silicosos ou fitólitos opalinos, de formas

Tabela 2. Comparação entre os táxons de Complexo Briza e Erianthecium Parodi baseada em caracteres da vista frontal da face abaxial da epiderme. nc = não computado. As letras entre parênteses identificam os caracteres da Tab. 4.

\begin{tabular}{|c|c|c|c|c|c|c|c|}
\hline $\begin{array}{r}\text { Táxons\Caracteres } \\
\text { cé }\end{array}$ & $\begin{array}{c}\text { Paredes } \\
\text { anticlinais das } \\
\text { células epidérmicas } \\
\text { logas (A) }\end{array}$ & $\begin{array}{l}\text { Presença e localização } \\
\text { das células suberosas } \\
\text { s }\end{array}$ & $\begin{array}{c}\text { Forma das } \\
\text { células } \\
\text { suberosas }(\mathrm{C})\end{array}$ & $\begin{array}{l}\text { Localização dos } \\
\text { corpos silicosos } \\
\text { (D) }\end{array}$ & $\begin{array}{l}\text { Forma dos corpos } \\
\text { silicosos costais } \\
\text { (E) }\end{array}$ & $\begin{array}{c}\text { Presença e localização } \\
\text { dos tricomas tipo } \\
\text { gancho }(\mathrm{F})\end{array}$ & $\begin{array}{c}\text { Forma das } \\
\text { células } \\
\text { subsidiárias dos } \\
\text { estômatos }(\mathrm{G})\end{array}$ \\
\hline B. ambigua & sinuosas & costal e intercostal & retangular & costal e intercostal & bilobada/polilobada & ausentes & trapezoidal \\
\hline B. bidentata & sinuosas & costal e intercostal & reniforme & costal e intercostal & suborbicular & costal e intercostal & oblonga \\
\hline B. brasiliensis & sinuosas & costal e intercostal & reniforme & costal e intercostal & suborbicular & ausentes & $\mathrm{nc}$ \\
\hline \multicolumn{2}{|c|}{ B. calotheca (banhado) sinuosas } & costal e intercostal & reniforme & costal e intercostal & bilobada/polilobada & costal e intercostal & trapezoidal \\
\hline B. calotheca (seco) & sinuosas & costal e intercostal & reniforme & costal e intercostal & bilobada/polilobada & costal e intercostal & trapezoidal \\
\hline B. humilis & sinuosas & ausentes & nc & costal & oblonga & costal & oblonga \\
\hline B. juergensii & sinuosas & costal e intercostal & reniforme & costal e intercostal & bilobada/polilobada & costal e intercostal & trapezoidal \\
\hline B. aff. juergensii & sinuosas & costal e intercostal & reniforme & costal e intercostal & bilobada/polilobada & costal e intercostal & trapezoidal \\
\hline B. lamarckiana & sinuosas & costal e intercostal & reniforme & costal e intercostal & suborbicular & costal e intercostal & $\mathrm{nc}$ \\
\hline B. aff. lamarckiana & sinuosas & costal e intercostal & reniforme & costal e intercostal & suborbicular & costal e intercostal & $\mathrm{nc}$ \\
\hline B. maxima & retas & ausentes & nc & costal & oblonga & costal & oblonga \\
\hline B. media & retas & ausentes & $\mathrm{nc}$ & costal & oblonga & costal & oblonga \\
\hline B. minor & retas & ausentes & nc & costal & oblonga & costal & oblonga \\
\hline B. monandra & retas & costal & retangular & costal & bilobada/polilobada & costal & oblonga \\
\hline B. paleapilifera & sinuosas & costal e intercostal & reniforme & costal e intercostal & suborbicular & costal & $\mathrm{nc}$ \\
\hline B. aff. paleapilifera & sinuosas & costal e intercostal & reniforme & costal e intercostal & suborbicular & costal e intercostal & nc \\
\hline B. poaemorpha & retas & costal & retangular & costal & bilobada/polilobada & costal & oblonga \\
\hline B. rufa & retas e sinuosas & costal & retangular & costal & bilobada/polilobada & costal & trapezoidal \\
\hline $\begin{array}{l}\text { B. subaristata } \\
\text { var. interrupta }\end{array}$ & sinuosas & costal e intercostal & reniforme & costal e intercostal & suborbicular & costal e intercostal & trapezoidal \\
\hline $\begin{array}{l}\text { B. subaristata } \\
\text { var. subaristata }\end{array}$ & sinuosas & costal e intercostal & reniforme & costal e intercostal & suborbicular & costal e intercostal & trapezoidal \\
\hline $\begin{array}{l}\text { B. uniolae } \\
\text { E. bulbosum }\end{array}$ & $\begin{array}{l}\text { sinuosas } \\
\text { retas }\end{array}$ & $\begin{array}{l}\text { costal e intercostal } \\
\text { costal }\end{array}$ & $\begin{array}{l}\text { reniforme } \\
\text { retangular }\end{array}$ & $\begin{array}{l}\text { costal e intercostal } \\
\text { costal }\end{array}$ & $\begin{array}{c}\text { suborbicular } \\
\text { bilobada/polilobada }\end{array}$ & $\begin{array}{c}\text { costal e intercostal } \\
\text { ausentes }\end{array}$ & $\begin{array}{c}\text { trapezoidal } \\
\text { oblonga }\end{array}$ \\
\hline
\end{tabular}




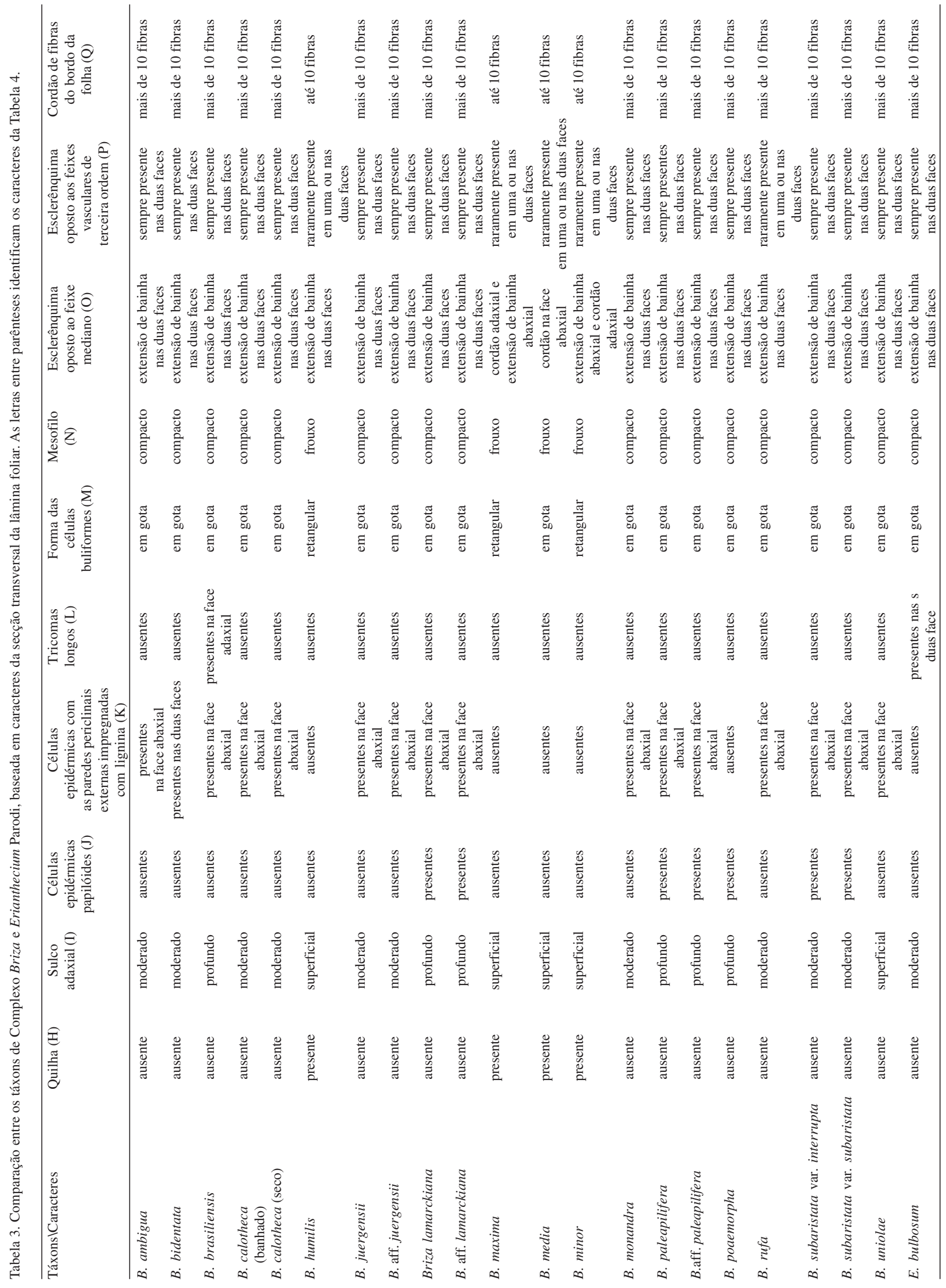


Tabela 4. Caracteres e estados utilizados na análise fenética.

\begin{tabular}{|c|c|c|c|}
\hline \multicolumn{2}{|l|}{ Caracteres } & \multicolumn{2}{|l|}{ Estados } \\
\hline A. Paredes anticlinais das células epidérmicas longas & $(0)$ retas & (1) sinuosas & (2) retas e sinuosas \\
\hline B. Presença e localização das células suberosas & (0) ausentes & (1) presentes na região costal & $\begin{array}{l}\text { (2) presentes nas regiões costal e } \\
\text { intercostal }\end{array}$ \\
\hline C. Forma das células suberosas da região costal & $(0)$ reniforme & (1) retangular & \\
\hline D. Localização dos corpos silicosos & (0) região costal & (1) região costal e intercostal & \\
\hline E. Forma dos corpos silicosos & (0) suborbicular & (1) bilobadalpolilobada & (2) oblonga \\
\hline F. Tricomas do tipo gancho & (0) ausentes & (1) presentes na região costal & $\begin{array}{l}\text { (2) presentes nas regiões costal e } \\
\text { intercostal }\end{array}$ \\
\hline G. Forma das células subsidiárias & (0) oblonga & (1) trapezoidal & \\
\hline H. Quilha & (0) ausente & (1) presente & \\
\hline I. Sulco adaxial & (0) superficial & (1) moderado & (2) profundo \\
\hline J. Células epidérmicas papilóides & (0) ausentes & (1) presentes & \\
\hline $\begin{array}{l}\text { K. Células epidérmicas com as paredes periclinais } \\
\text { externas impregnadas com lignina }\end{array}$ & (0) ausente & (1) presente na face abaxial & (2) presente nas duas faces \\
\hline L. Tricomas longos & (0) ausentes & (1) presentes nas duas faces & (2) presentes na face adaxial \\
\hline M. Forma das células buliformes & (0) em gota & (1) retangular & \\
\hline N. Mesofilo & (0) compacto & (1) frouxo & \\
\hline O. Esclerênquima oposto ao feixe mediano & $\begin{array}{l}\text { (0) extensão de bainha } \\
\text { nas duas faces }\end{array}$ & (1) cordão na face abaxial & $\begin{array}{l}\text { (2) cordão na face adaxial e extensão } \\
\text { de bainha na face abaxial }\end{array}$ \\
\hline P. Esclerênquima oposto aos feixes de $3^{\mathrm{a}}$ ordem & $\begin{array}{l}\text { (0) raramente presente } \\
\text { em uma ou nas duas faces }\end{array}$ & (1) sempre presente nas duas faces & \\
\hline Q. Cordão de esclerênquima do bordo da lâmina foliar & (0) até 10 fibras & (1) mais de 10 fibras & \\
\hline
\end{tabular}

Tabela 5. Matriz de dados dos 22 táxons $\times 17$ características utilizados na análise de agrupamentos. Os acrônimos correspondem às espécies da Tabela 1 e as letras e números correspondem à lista de caracteres e estados apresentados na Tabela 4. O número 9 corresponde à característica não computada (nc).

\begin{tabular}{llllllllllllllllll}
\hline Táxonslcaracteres & $\mathrm{A}$ & $\mathrm{B}$ & $\mathrm{C}$ & $\mathrm{D}$ & $\mathrm{E}$ & $\mathrm{F}$ & $\mathrm{G}$ & $\mathrm{H}$ & $\mathrm{I}$ & $\mathrm{J}$ & $\mathrm{K}$ & $\mathrm{L}$ & $\mathrm{M}$ & $\mathrm{N}$ & $\mathrm{O}$ & $\mathrm{P}$ & $\mathrm{Q}$ \\
\hline AMBI & 1 & 2 & 1 & 1 & 1 & 0 & 1 & 0 & 1 & 0 & 1 & 0 & 0 & 0 & 0 & 1 & 1 \\
BIDE & 1 & 2 & 0 & 1 & 0 & 2 & 0 & 0 & 1 & 0 & 2 & 0 & 0 & 0 & 0 & 1 & 1 \\
BRAS & 1 & 2 & 0 & 1 & 0 & 0 & 9 & 0 & 2 & 0 & 1 & 2 & 0 & 0 & 0 & 1 & 1 \\
CAL1 & 1 & 2 & 0 & 1 & 1 & 2 & 1 & 0 & 1 & 0 & 1 & 0 & 0 & 0 & 0 & 1 & 1 \\
CAL2 & 1 & 2 & 0 & 1 & 1 & 2 & 1 & 0 & 1 & 0 & 1 & 0 & 0 & 0 & 0 & 1 & 1 \\
HUMI & 1 & 0 & 9 & 0 & 2 & 1 & 0 & 1 & 0 & 0 & 0 & 0 & 1 & 1 & 0 & 0 & 0 \\
JUE1 & 1 & 2 & 0 & 1 & 1 & 2 & 1 & 0 & 1 & 0 & 1 & 0 & 0 & 0 & 0 & 1 & 1 \\
JUE2 & 1 & 2 & 0 & 1 & 1 & 2 & 1 & 0 & 1 & 0 & 1 & 0 & 0 & 0 & 0 & 1 & 1 \\
LAM1 & 1 & 2 & 0 & 1 & 0 & 2 & 9 & 0 & 2 & 1 & 1 & 0 & 0 & 0 & 0 & 1 & 1 \\
LAM2 & 1 & 2 & 0 & 1 & 0 & 2 & 9 & 0 & 2 & 1 & 1 & 0 & 0 & 0 & 0 & 1 & 1 \\
MAXI & 0 & 0 & 9 & 0 & 2 & 1 & 0 & 1 & 0 & 0 & 0 & 0 & 1 & 1 & 0 & 0 & 0 \\
MEDI & 0 & 0 & 9 & 0 & 2 & 1 & 0 & 1 & 0 & 0 & 0 & 0 & 0 & 1 & 2 & 0 & 0 \\
MINO & 0 & 0 & 9 & 0 & 2 & 1 & 0 & 1 & 0 & 0 & 0 & 0 & 1 & 1 & 1 & 0 & 0 \\
MONA & 0 & 1 & 1 & 0 & 1 & 1 & 0 & 0 & 1 & 0 & 1 & 0 & 0 & 0 & 0 & 1 & 1 \\
PAL1 & 1 & 2 & 0 & 1 & 0 & 2 & 9 & 0 & 2 & 1 & 1 & 0 & 0 & 0 & 0 & 1 & 1 \\
PAL2 & 1 & 2 & 0 & 1 & 0 & 2 & 9 & 0 & 2 & 1 & 1 & 0 & 0 & 0 & 0 & 1 & 1 \\
POAE & 0 & 1 & 1 & 0 & 1 & 1 & 0 & 0 & 2 & 1 & 0 & 0 & 0 & 0 & 0 & 1 & 1 \\
RUFA & 2 & 1 & 1 & 0 & 1 & 1 & 1 & 0 & 1 & 0 & 1 & 0 & 0 & 0 & 0 & 1 & 1 \\
SUB1 & 1 & 2 & 0 & 1 & 0 & 2 & 1 & 0 & 1 & 1 & 1 & 0 & 0 & 0 & 0 & 1 & 1 \\
SUB2 & 1 & 2 & 0 & 1 & 0 & 2 & 1 & 0 & 1 & 1 & 1 & 0 & 0 & 0 & 0 & 1 & 1 \\
UNIO & 1 & 2 & 0 & 1 & 0 & 2 & 1 & 0 & 0 & 0 & 1 & 0 & 0 & 0 & 0 & 1 & 1 \\
BULB & 0 & 1 & 1 & 0 & 1 & 0 & 0 & 0 & 1 & 0 & 0 & 1 & 0 & 0 & 0 & 1 & 1 \\
\hline
\end{tabular}

variadas (Piperno \& Pearsall 1998; Madella et al. 2005). A forma dos corpos silicosos não é influenciada por fatores ambientais, indicando que é controlada geneticamente, possuindo, portanto, considerável potencial taxonômico e diagnóstico (Prychid et al. 2004). Os corpos silicosos, que nas espécies eurasiáricas de Briza são oblongos (Fig. 5) e nas americanas são suborbiculares (Fig. 3) ou bilobados/ polilobados (Fig. 4), constituem-se também num caráter importante para separar as espécies eurasiáticas das americanas.

Embora as células silicificadas e suberosas sejam comuns nas gramíneas, formando um par sílico-suberoso (Vieira et al. 2002), em algumas espécies as células curtas podem estar representadas apenas por células silicificadas, como evidenciado por López \& Devesa (1991) em Chaetopogon fasciculatus (Link) Hayek. e nas espécies eurasiáticas Briza maxima, B. media, B. minor (Fig. 2). e B. humilis. Estas não apresentam células suberosas na face abaxial da epiderme, mostrando reação negativa para suberina com Sudan III. Entretanto, este resultado discorda dos apresentados por Matthei (1975), que verificou células suberosas nas espécies eurasiáticas de Briza. Suas ilustrações para células suberosas destas espécies não mostram claramente células suberosas com seu formato curto típico. Segundo Metcalfe (1960), Lohauss (1905) identificou células suberosas nas espécies eurasiáticas B. maxima, B. media e B. minor, e da americana $B$. triloba Nees (considerada sinônimo de B. subaristata). Porém, analisando detalhadamente o trabalho de Lohauss (1905), comprovou-se que o mesmo citou a presença de células suberosas apenas para a espécie americana. Na verdade, a ausência de células suberosas nas espécies eurasiáticas comprova a importância desse caráter para separá-las das americanas. Nestas as células suberosas variam na forma, podendo ser reniformes (Fig. 3) ou retangulares (Fig. 4), fato também observado em diferentes subgêneros de Bromus L. por Acedo \& Llamas (2001). Porém, não foi possível associar esse caráter a nenhum agrupamento infragenérico das espécies americanas de Briza proposto anteriormente por diferentes autores, como seções (Longhi-Wagner 1987) ou subgêneros (Parodi 1920).

As células longas intercostais da face abaxial da epiderme das espécies estudadas diferem na sinuosidade das paredes anticlinais. Briza maxima, B. media (Fig. 5) e B. minor, assim como B. poaemorpha, B. monandra e Erianthecium bulbosum (Fig. 12,15), apresentam células epidérmicas longas intercostais com paredes anticlinais retas. Briza rufa (Fig. 7) é a única espécie com paredes anticlinais sinuosas na região próxima à zona costal, e retas, na porção mediana 
da zona intercostal. Na eurasiática, B. humilis (Fig. 9) e nas demais espécies americanas, as células epidérmicas longas têm paredes anticlinais sinuosas (Fig. 6, 16). Por sua vez, as paredes anticlinais das células epidérmicas costais são geralmente sinuosas (Fig. 3), exceto em B. minor, B. media (Fig. 5) e E. bulbosum, cujas paredes são retas. Estes resultados assemelham-se aos de Matthei (1975) para a as espécies do Complexo Briza, porém esse autor não apresentou dados sobre B. bidentata e B. brasiliensis, excluídas do complexo. Corroboram também com os resultados de Watson \& Dallwitz (1992) para B. maxima, B. minor e B. subaristata. Fisher (1939) relacionou a sinuosidade da parede à prevenção do colapso da mesma sob deficiência hídrica, porém, não se conhece comprovação experimental a respeito. Das espécies analisadas, B. calotheca (Fig. 16) e B. juergensii, que ocorrem em
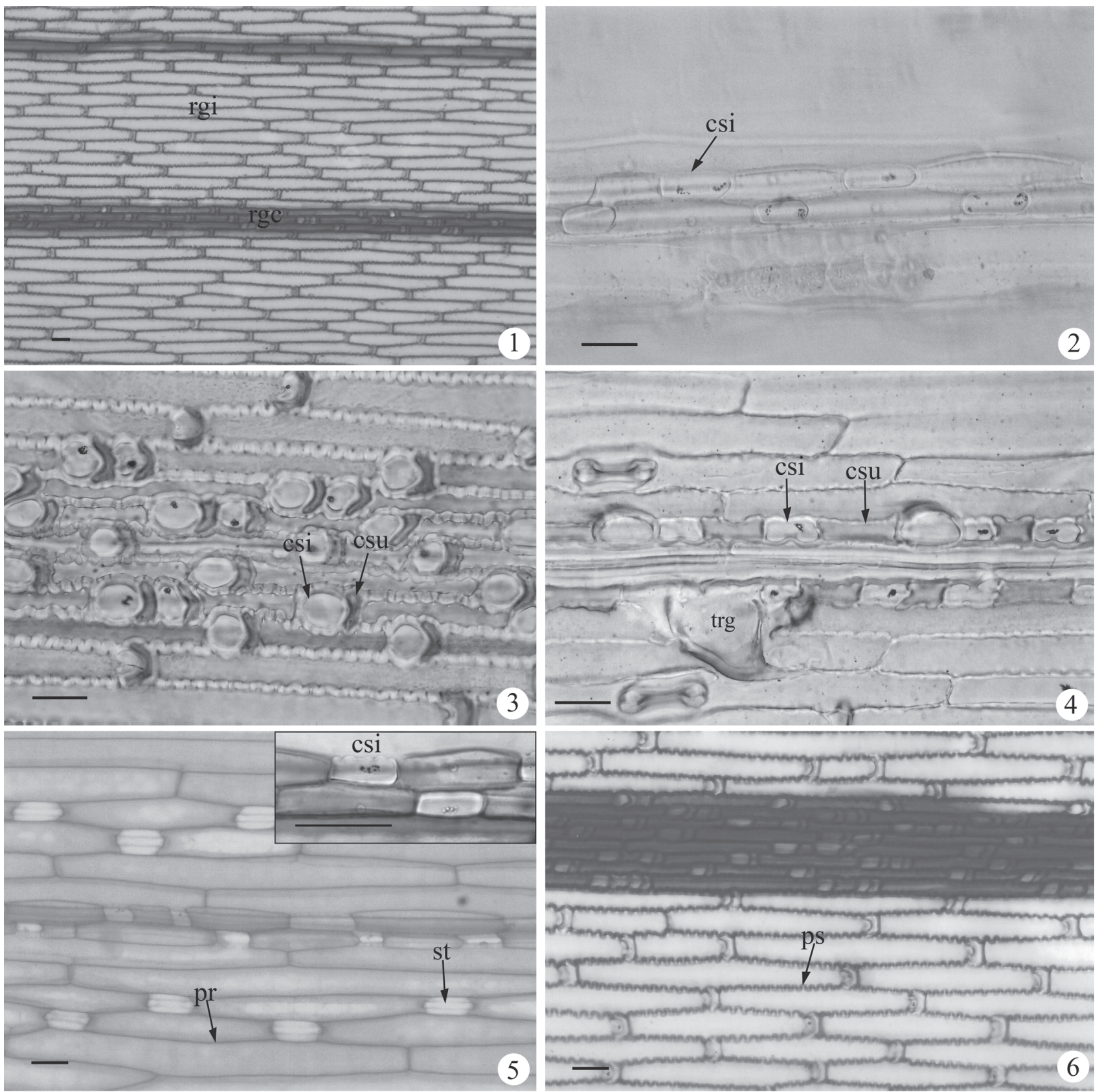

Figuras 1-6. Vista frontal da face abaxial da epiderme foliar. 1. Briza subaristata Lam. var. subaristata, zonação costal-intercostal da epiderme. 2. Briza minor L., corpos silicosos oblongos. 3. Briza lamarckiana Nees, paredes anticlinais das células costais sinuosas, corpos silicosos suborbiculares na região costal, células suberosas reniformes. 4. Briza rufa (J. Presl) Steud., células suberosas retangulares, corpos silicosos bilobados/polilobados, tricomas gancho na região costal. 5. Briza media L., paredes anticlinais das células longas costais e intercostais retas, estômatos com células subsidiárias oblongas, corpos silicosos oblongos, células curtas apenas na região costal. 6. Briza subaristata var. interrupta (Hack.) Roseng., paredes anticlinais das células longas costais e intercostais sinuosas, células curtas nas regiões costal e intercostal. Barra $=30 \mu \mathrm{m} ; \mathrm{csi}=$ corpo silicoso; $c$ csu = célula suberosa; $\mathrm{pr}=$ parede reta; $\mathrm{ps}=$ parede sinuosa; rgc $=$ região costal; rgi= região intercostal; st = estômato; trg = tricoma gancho. 
ambientes úmidos, apresentam células epidérmicas com as paredes anticlinais sinuosas, fato que contraria a teoria de Fisher (1939). Ellis (1979) ressaltou a necessidade do uso de outros caracteres como subsídio à taxonomia, devido às variações genotípicas e fenotípicas desse caráter. Apesar do limitado valor taxonômico do mesmo, Church (1949) distinguiu o gênero Glyceria $\mathrm{R}$. Br., com paredes anticlinais das células longas retas, de Puccinellia Parl. e Torreyochloa G.L. Church, com paredes anticlinais sinuosas. Finot et al. (2006) utilizaram esse caráter para separar espécies de Trisetum Pers., também um gênero de Pooideae.

A presença e a localização de tricomas unicelulares do tipo gancho apresentam variações nas espécies estudadas. Estes não ocorrem em Briza brasiliensis (Fig. 8), B. ambigua e Erianthecium bulbosum. Nas demais espécies, encontram-se por toda a lâmina foliar, como em de B. uniolae (Fig. 10) ou restritos à região costal, como nas espécies eurasiáticas (Fig. 9, Tab. 2), além de B. bidentata, B. monandra, B. poaemorpha, B. paleapilifera, B. aff. paleapilifera e $B$. rufa, sendo esse caráter constante nas espécies. Por outro lado, a quantidade desse tipo de tricoma variou em diferentes indivíduos da mesma espécie, como em B. uniolae. Aiken \& Lefkovitch (1983), ressaltaram que a quantidade de tricomas do tipo gancho em Festuca altaica Trin. é um caráter plástico, não sendo útil para fins diagnósticos. Tricomas do tipo gancho também foram encontrados nos bordos das lâminas foliares da maioria das espécies estudadas (Fig. 11), exceto em E. bulbosum e B. brasiliensis.

Tricomas longos ocorrem apenas na epiderme de Erianthecium bulbosum, em ambas as faces (Fig. 12, 17) e de Briza brasiliensis (Fig. 18), apenas na face adaxial. A presença ou não deste tipo de tricomas foi utilizada para distinguir espécies de Hordeum (Cai et al. 2003) e subespécies de Aristida stricta Michx. (Kesler et al. 2003). Porém, em outros grupos de Poaceae, tal característica não apresenta a mesma importância. Segundo Reimer \& CotaSánchez (2007), a presença ou ausência de tricomas longos não reflete relações taxonômicas na subfamília Danthonioideae. Esse caráter também não reflete relações taxonômicas no grupo estudado, pois sua ausência foi comum às demais espécies americanas e eurasiáticas.

Os complexos estomáticos são citados como caráter diagnóstico em Poaceae, tanto pela sua freqüência e distribuição na epiderme foliar, quanto pela forma das células subsidiárias (Metcalfe 1960; Ellis 1979; Palmer \& Tucker 1981). Nas espécies analisadas podem ser distribuídos em uma (Fig. 13) a várias (Fig. 14) fileiras longitudinais na zona intercostal, com as células subsidiárias oblongas ou trapezoidais como é característico para gramíneas festucóides (Ellis 1979; 1987; Watson \& Johnston 1978) sendo a forma trapezoidal a mais comum (Fig. 16, Tab. 2). Porém, as eurasiáticas Briza humilis, B. maxima, B. media (Fig. 5) e B. minor, assim como as americanas B. bidentata, B. monandra, B. poaemorpha e Erianthecium bulbosum (Fig. 15), mostram complexos estomáticos com células subsidiárias oblongas. Em grande parte das espécies estudadas, as folhas são anfiestomáticas (Fig. 19). Entretanto, em B. lamarckiana, B. aff. lamarckiana, B. paleapilifera (Fig. 20), B. aff. paleapilifera e B. brasiliensis (Fig. 18) os estômatos estão apenas na face adaxial da epiderme, caracterizando suas folhas como epiestomáticas. Watson \& Dallwitz (1992) ressaltaram que os estômatos inexistem ou, se presentes, podem ser raros ou comuns na face abaxial da epiderme foliar das três espécies de Briza analisadas, concordando com os resultados obtidos. Por outro lado, de acordo com Matthei (1975), não ocorrem estômatos na face abaxial de B. subaristata e B. uniolae, diferente dos resultados aqui obtidos, onde foram encontrados estômatos na face abaxial nestas duas espécies, embora raros. Isto pode ser devido ao fato dos mesmos estarem ausentes em áreas particulares da lâmina foliar, conforme salientado por Ellis (1979) e observado no presente estudo.

Secção transversal da lâmina foliar - Todas as espécies analisadas têm lâminas com sulcos adaxiais intercostais, que variam em profundidade. A maioria das espécies apresenta sulcos moderados (Fig. 30, Tab. 3) que atingem a metade da espessura do mesofilo. Por sua vez, Briza brasiliensis, B. lamarckiana (Fig. 29), B. aff. lamarckiana, B. poaemorpha (Fig. 21), B. paleapilifera (Fig. 20) e B. aff. paleapilifera mostram sulcos profundos, com mais da metade da espessura do mesofilo. Em B. maxima, B. media (Fig.19), B. minor (Fig. 28), B. humilis e B. uniolae (Fig. 27) os sulcos são superficiais. Metcalfe (1960) relatou a existência de uma correlação positiva entre a presença de saliências e sulcos bem desenvolvidos na lâmina foliar e a capacidade de enrolamento da mesma, ressaltando sua importância como caráter diagnóstico para espécies. Por outro lado, Ma et al. (2005) demonstraram que esse caráter não foi eficaz para separar Aniselytron Merr. de Calamagrostis Adans., concordando com os resultados aqui obtidos, onde não foi possível delimitar os grupos de espécies eurasiáticas e americanas e nem formar subgrupos destas.

I. Epiderme - A lâmina foliar das espécies analisadas apresenta a epiderme uniestratificada. Geralmente, esta é constituída por células homogêneas quanto à forma e tamanho nas duas faces, excetuando-se as células buliformes. Porém, na face adaxial de Briza poaemorpha (Fig. 21), B. lamarckiana, B. aff. lamarckiana, B. subaristata (Fig. 24), B. paleapilifera (Fig. 20) e B. aff. paleapilifera aparecem células epidérmicas papilóides assim denominadas por não se tratar de papilas típicas conforme Ellis (1979) e Alquini et al. (2006).

As paredes periclinais externas das células epidérmicas da face abaxial estão impregnadas por lignina na maioria das espécies americanas (Fig. 25, Tab. 3), com exceção de Briza poaemorpha (Fig. 21) e Erianthecium bulbosum (Fig. 17). Apenas B. bidentata (Fig. 22) tem paredes com lignina nas duas faces, excetuando-se as células buliformes. Por outro lado, nas eurasiáticas B. maxima (Fig. 23), B. media 
(Fig. 26), B. minor e $B$. humilis não foi encontrada essa impregnação. Células epidérmicas impregnadas com lignina também foram relatadas para Axonopus P. Beauv. (Silva \& Alquini 2003), para Pharus lappulacens Aubl., por Vieira et al. (2002), e para Tristachya leiostachya Nees e Loudetiopsis chrysothrix (Nees) Conert, por Alvarez et al. (2005). O espessamento das paredes das células epidérmicas é referido como freqüente em plantas de ambientes secos (Fahn \& Cutler 1992). Entretanto, B. calotheca, B. juergensii e $B$. aff. juergensii, comuns em ambientes úmidos, possuem células epidérmicas espessadas, sugerindo a ausência de correlação entre esta característica e a resistência à perda de água, nestas espécies.

As células buliformes são abundantes na face adaxial da epiderme das espécies estudadas, como na maioria das gramíneas (Ellis 1976). Porém, não foram encontradas na região da nervura central como comum na família. Estão dispostas ao longo de toda a face adaxial da epiderme, geralmente em grupos regulares e bem distintas das demais células epidérmicas, por possuírem forma de gota ou trapezoidal, com a parede periclinal externa menor que a interna (Fig. 27). Entretanto, Briza brasiliensis, B. maxima,
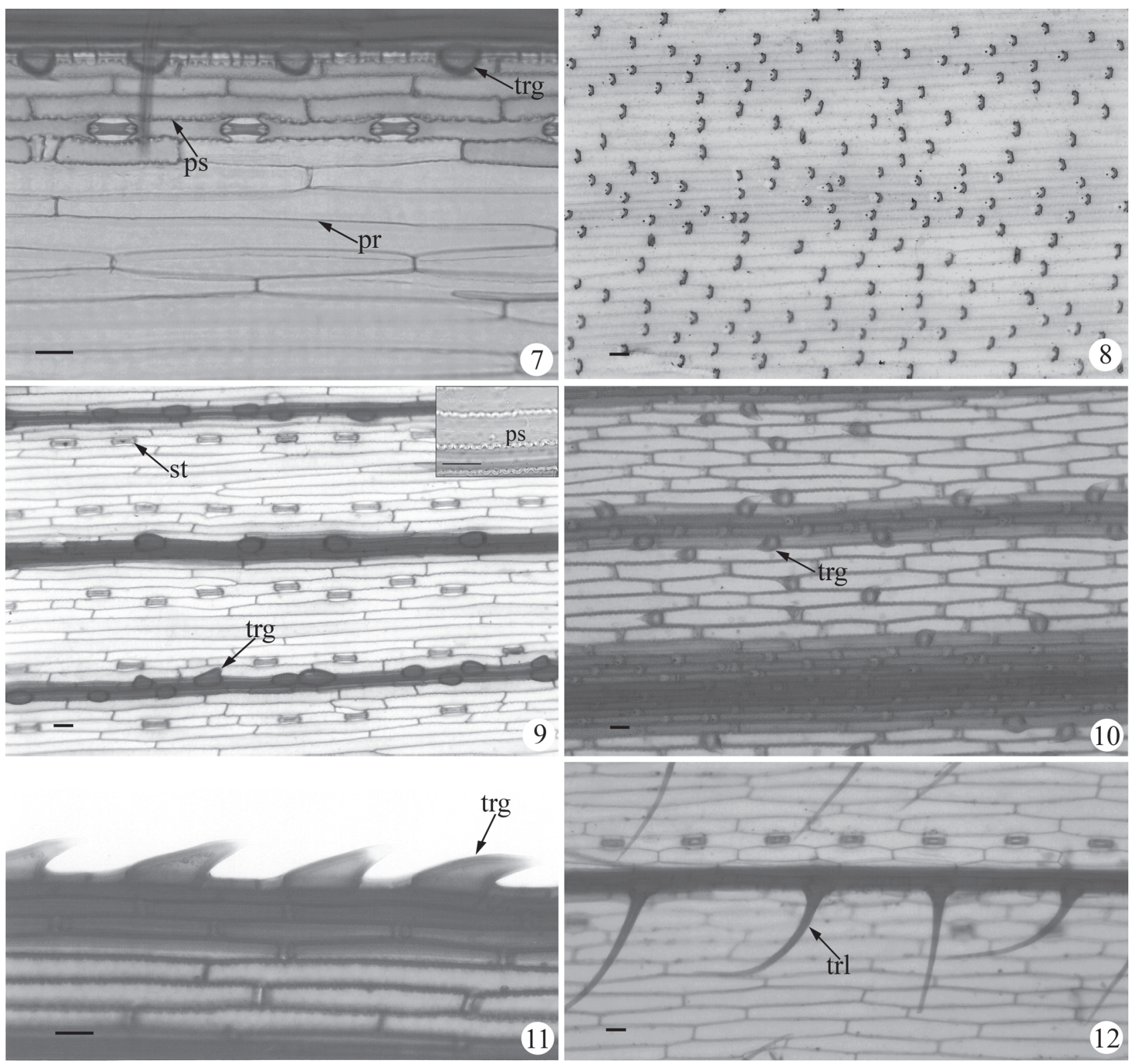

Figuras 7-12. Vista frontal da face abaxial da epiderme foliar. 7. Briza rufa (J. Presl) Steud., paredes anticlinais das células longas intercostais sinuosas próximo às nervuras e retas na zona mediana da região intercostal, tricomas gancho na região costal. 8. Briza brasiliensis (Nees ex Steud.) Ekman, sem tricomas gancho. 9. Briza humilis M. Bieb., tricomas gancho apenas na região costal, detalhe das paredes anticlinais das células longas intercostais sinuosas. 10. Briza uniolae (Nees) Nees ex Steud., tricomas gancho nas regiões costal e intercostal. 11. Briza lamarckiana Nees, tricomas gancho no bordo da lâmina foliar. 12. Erianthecium bulbosum Parodi, tricomas longos na região costal. Barra $=30 \mu \mathrm{m} ;$ pr $=$ parede reta; $\mathrm{ps}=$ parede sinuosa; trg $=$ tricoma gancho; trl $=$ tricoma longo; st $=$ estômato. 
B. minor e B. humilis apresentam forma retangular (Fig. 28), não se destacando muito das demais células da epiderme. Provavelmente devido a este fato, Watson \& Dallwitz (1992) descreveram a face abaxial da epiderme de B. maxima e B. minor como extensivamente buliforme.

II. Mesofilo - Em todas as espécies analisadas, o mesofilo não mostra distinção entre parênquimas paliçádico e esponjoso, concordando com Cutter (1987) e Ellis (1976), que referiram esse padrão como típico para Poaceae. As células do mesofilo estão irregularmente distribuídas ao redor dos feixes vasculares, característica de espécies do tipo fotossintético $\mathrm{C}_{3}$ (Brown 1958; Ellis 1987). O clorênquima geralmente apresenta poucos espaços intercelulares, formando um mesofilo compacto (Fig. 30). Porém, nas espécies eurasiáticas as células do clorênquima apresentam um arranjo mais frouxo, devido à presença de grandes espaços intercelulares (Fig. 31, 38), caráter este importante para distinguí-las das espécies americanas do Complexo.

III. Sistema Vascular - Os feixes vasculares estão situados em posição aproximadamente eqüidistante entre as duas faces da lâmina foliar e são de primeira, segunda e terceira ordens (Metcalfe 1960). Os feixes de primeira ordem são caracterizados por apresentarem elementos de metaxilema conspícuos, lacunas de protoxilema e variados graus de esclerificação do floema (Fig. 33). Os de segunda ordem possuem um ou dois elementos de metaxilema, porém não exibem lacunas de protoxilema (Fig. 34). Os feixes de terceira ordem são menores que os anteriores e possuem elementos de metaxilema pouco conspícuos (Fig. 35). Em todas as espécies estudadas ocorre apenas um feixe vascular mediano, sempre de primeira ordem (Fig. 29). Todos os feixes vasculares estão envolvidos por duas bainhas, a interna mestomática (N.L. de Menezes, com. pessoal) com células de paredes esclerificadas e a externa, parenquimática, com as células de paredes delgadas (Fig. 33-35), como é característico da subfamília Pooideae (Schwendener 1890; Brown 1975; Escalona 1991; López \& Devesa 1991).

As espécies eurasiáticas de Briza apresentam a região do feixe vascular mediano bem distinta do restante da lâmina foliar, pela presença de quilha (Fig. 37). Nas espécies americanas, a região do feixe vascular mediano é pouco evidente (Fig. 24). A quilha é caracterizada por uma expansão de parênquima incolor ou de esclerênquima na região abaxial da nervura central, formando uma saliência visível
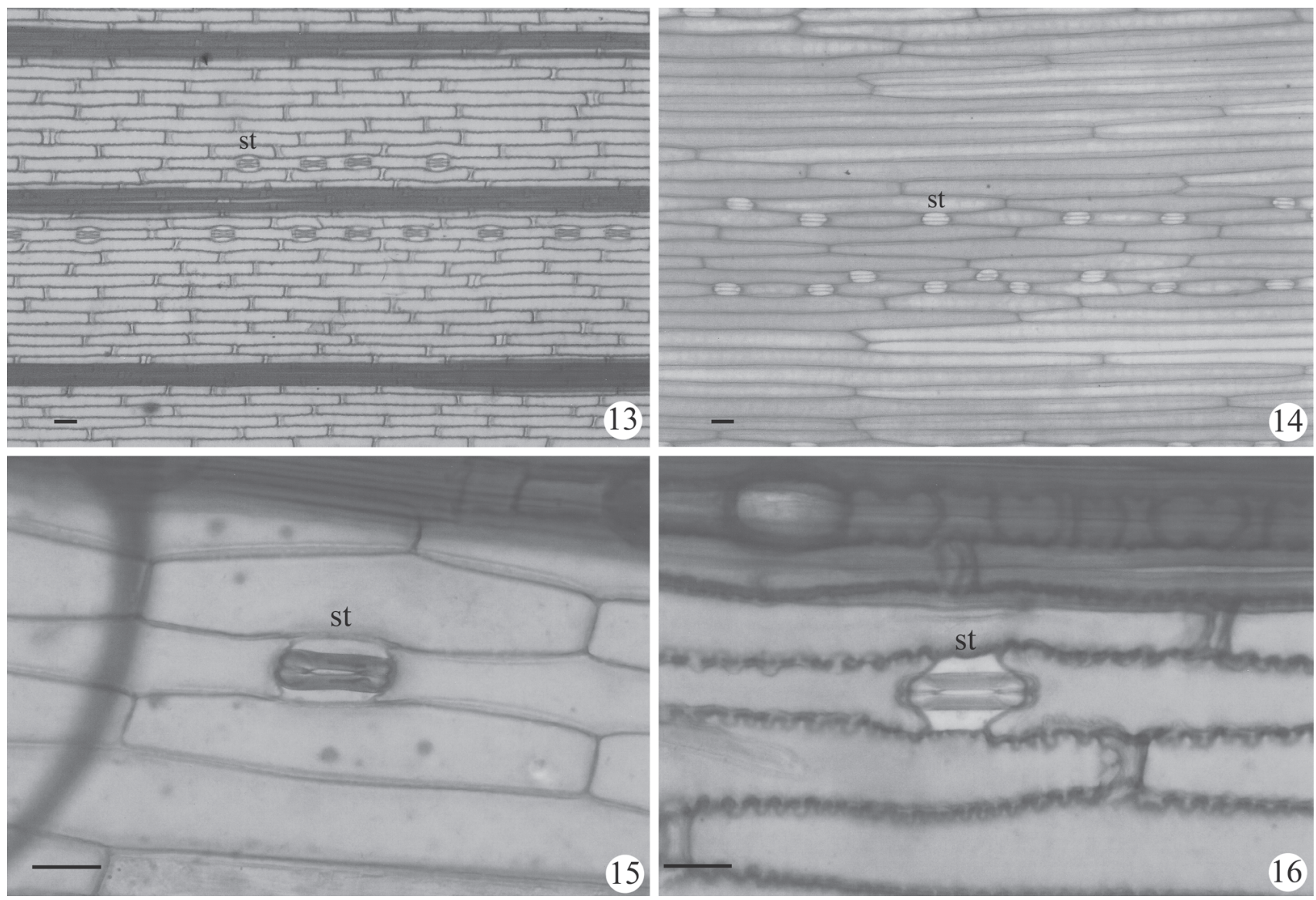

Figuras 13-16. Vista frontal da face abaxial da epiderme foliar. 13. Briza bidentata (J. Presl) Henr., uma fileira longitudinal de estômatos em cada região intercostal. 14. Briza maxima L., várias fileiras de estômatos em cada região intercostal. 15. Erianthecium bulbosum Parodi, estômato com células subsidiárias oblongas. 16. Briza calotheca (Trin.) Hack., estômato com células subsidiárias trapezoidais, paredes anticlinais das células longas intercostais sinuosas. Barra = 30 um; $\mathrm{pr}=$ parede reta; $\mathrm{ps}=$ parede sinuosa; $\mathrm{st}=$ estômato. 

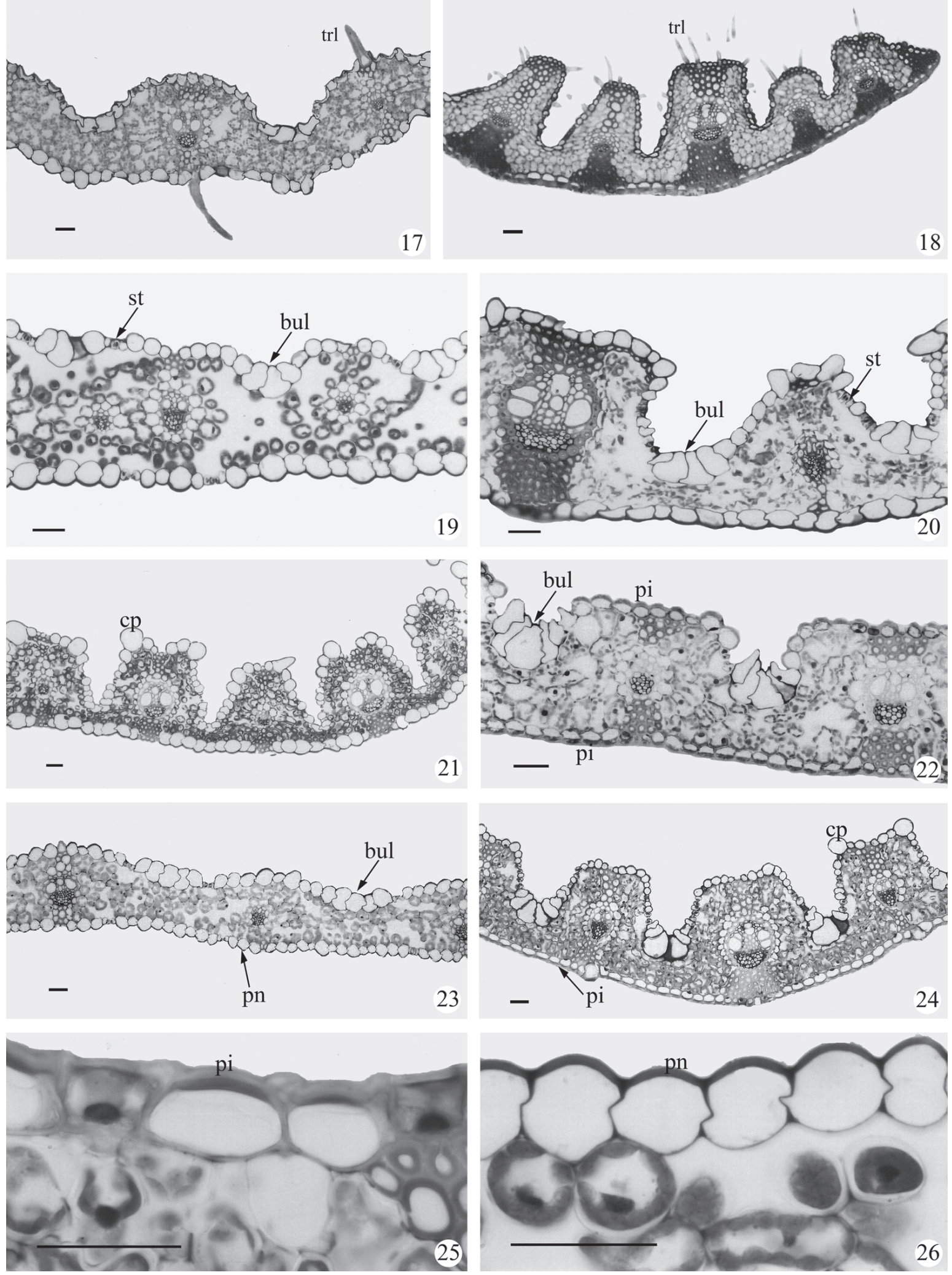

Figuras 17-26. Secção transversal da lâmina foliar. 17. Erianthecium bulbosum Parodi, tricomas longos nas duas faces. 18. Briza brasiliensis (Nees ex Steud.) Ekman, tricomas longos na face adaxial . 19 e 16. Briza media L. 19. folha anfiestomática, sulcos adaxiais superficiais. 26. células epidérmicas sem impregnação de lignina. 20. Briza paleapilifera Parodi, folha epiestomática, sulcos adaxiais profundos. 21. Briza poaemorpha (J.Presl) Henr. células epidérmicas papilóides, sulcos adaxiais profundos. 22. Briza bidentata Roseng., Arrill. \& Izag., impregnação de lignina nas células epidérmicas de ambas as faces, células buliformes em gota. 23. Briza maxima L., células epidérmicas sem impregnação de lignina nas duas faces, células buliformes retangulares. 24-25. Briza subaristata Lam. var. subaristata. 24. Extensões de bainha em I no feixe vascular mediano, células epidérmicas papilóides. 25. Células da face abaxial impregnadas com lignina. Barra $=30 \mu \mathrm{m} ; \mathrm{cp}=$ célula epidérmica papilóide; $\mathrm{pi}=$ parede impregnada; $\mathrm{pn}=$ parede não impregnada; $\mathrm{st}$ = estômato; trl = tricoma longo. 
externamente como uma nervura central mais destacada das demais (Ellis 1976). Fisher (1939) constatou que caracteres relacionados à quilha foram de grande relevância para separar espécies de Chloris Sw. Ma et al. (2005) separaram o gênero Aniselytron de Calamagrostis pela presença de quilha no primeiro. A presença de quilha verificada apenas nas espécies eurasiáticas de Briza, corrobora as informações de Matthei (1975), e auxilia na definição das relações taxonômicas do Complexo Briza.

O feixe vascular mediano está acompanhado por extensões de bainha esclerenquimática nas duas faces da lâmina foliar, em boa parte das espécies analisadas (Fig. 24). Em Briza minor (Fig. 37), em direção a face abaxial ocorre um cordão de esclerênquima isolado e oposto ao feixe vascular mediano. Por sua vez, B. media (Fig. 38) apresenta extensão de bainha na face abaxial e cordão oposto ao feixe vascular mediano na face adaxial.

Nos feixes vasculares de terceira ordem das espécies eurasiáticas de Briza, o esclerênquima oposto ao feixe raramente está presente, em uma ou nas duas faces, e, se presente, aparece como cordões arredondados (Fig. 39). As espécies americanas têm uma maior quantidade de esclerênquima na lâmina foliar geralmente com extensões de bainha esclerenquimática para a face abaxial e cordões alongados na face adaxial (Fig. 36). O tecido esclerenquimático também pode estar presente nos bordos da lâmina foliar, na forma de cordões, que podem variar na quantidade e arranjo das fibras (Ellis 1976). Nas espécies eurasiáticas analisadas, esses cordões estão isolados dos feixes e são constituídos por um grupo de poucas fibras, sem arranjo definido (Fig. 31), enquanto nas americanas, os cordões apresentam muitas fibras, chegando a formar
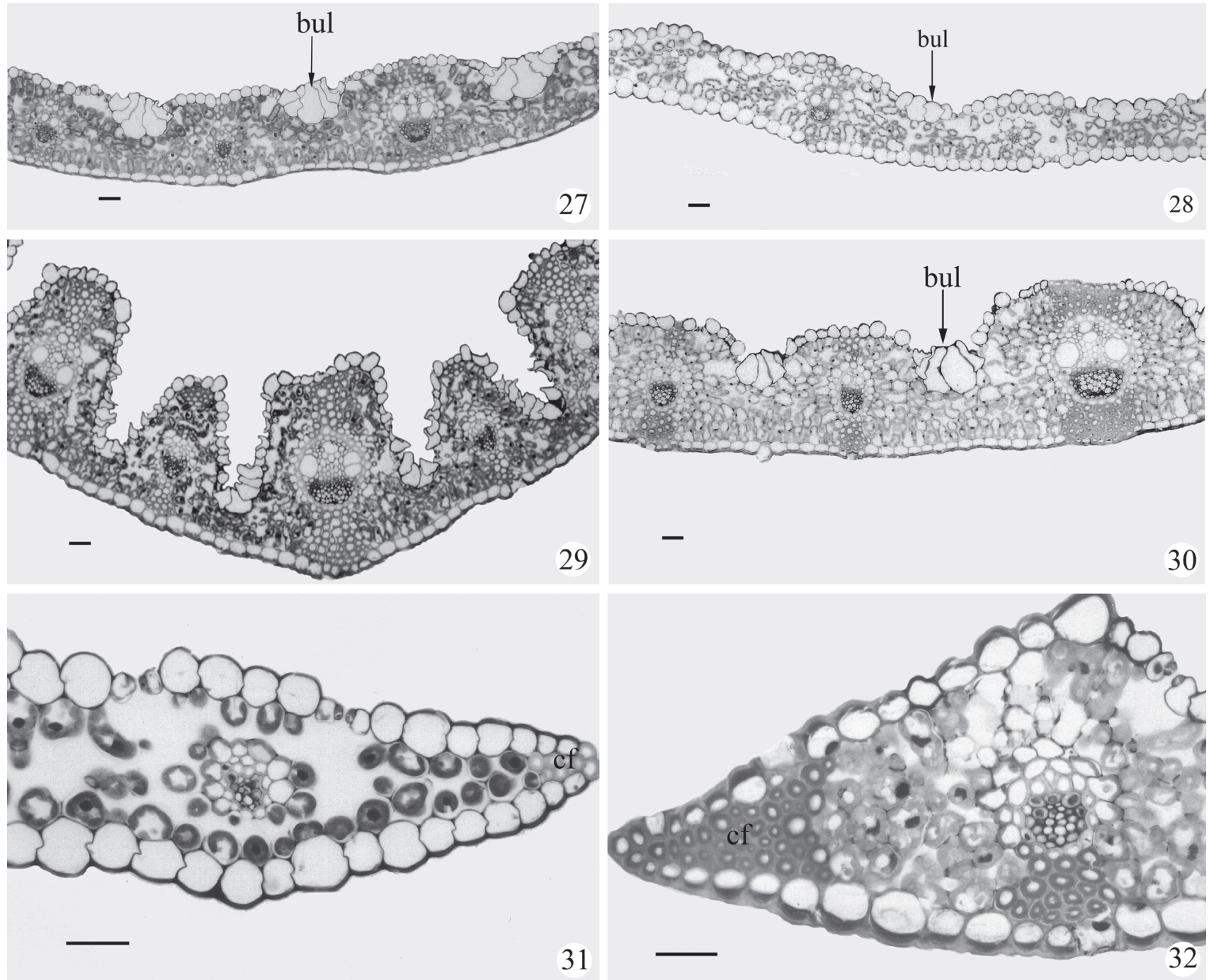

Figuras 27-32. Secção transversal da lâmina foliar. 27. Briza uniolae (Nees) Nees ex Steud., células buliformes em forma de gota, sulcos adaxiais superficiais. 28. Briza minor L., células buliformes retangulares e sulcos adaxiais superficiais. 29. Briza lamarckiana Nees, feixe vascular mediano, sulcos adaxiais profundos. 30. Briza calotheca (Trin.) Hack., sulcos adaxiais moderados, mesofilo compacto, células buliformes em gota. 31 . Briza media L., cordão de esclerênquima do bordo da folha com menos de dez fibras, mesofilo frouxo. 32. Briza subaristata Lam. var. subaristata, cordão de esclerênquima do bordo da lâmina com mais dez fibras. Barra $=30 \mu \mathrm{m} ;$ bul $=$ células buliformes; $\mathrm{cf}=$ cordão de fibras; st $=$ estômato. 
um casquete pontiagudo (Fig. 32). Soderstrom (1967) encontrou uma menor quantidade de esclerênquima em lâminas foliares de espécies anuais de Muhlenbergia Schreb. Das quatro espécies eurasiáticas analisadas, apenas $B$. media é perene, mas também apresenta pequena quantidade de esclerênquima. Portanto, acredita-se que tal caráter não esteja relacionado diretamente, ou exclusivamente, à duração do ciclo de vida das plantas, e que seja um caráter de importância taxonômica para o grupo.

Análise fenética - Os resultados apresentados no fenograma (Fig. 40) mostram que os caracteres da face abaxial da epiderme relativos à presença ou ausência de células suberosas e à forma dos corpos silicosos são úteis para distinguir o grupo das espécies eurasiáticas do grupo das americanas. O mesmo vale para alguns caracteres relacionados à secção transversal da lâmina foliar, como forma da lâmina, quantidade de fibras e estrutura do mesofilo. Os dois grupos apresentam um baixo índice de similaridade (22\%), evidenciando grandes diferenças em relação aos caracteres analisados.

A distinção entre o grupo das espécies eurasiáticas do Complexo Briza e o grupo das americanas concorda com os resultados obtidos por King (1986), com base em análises de
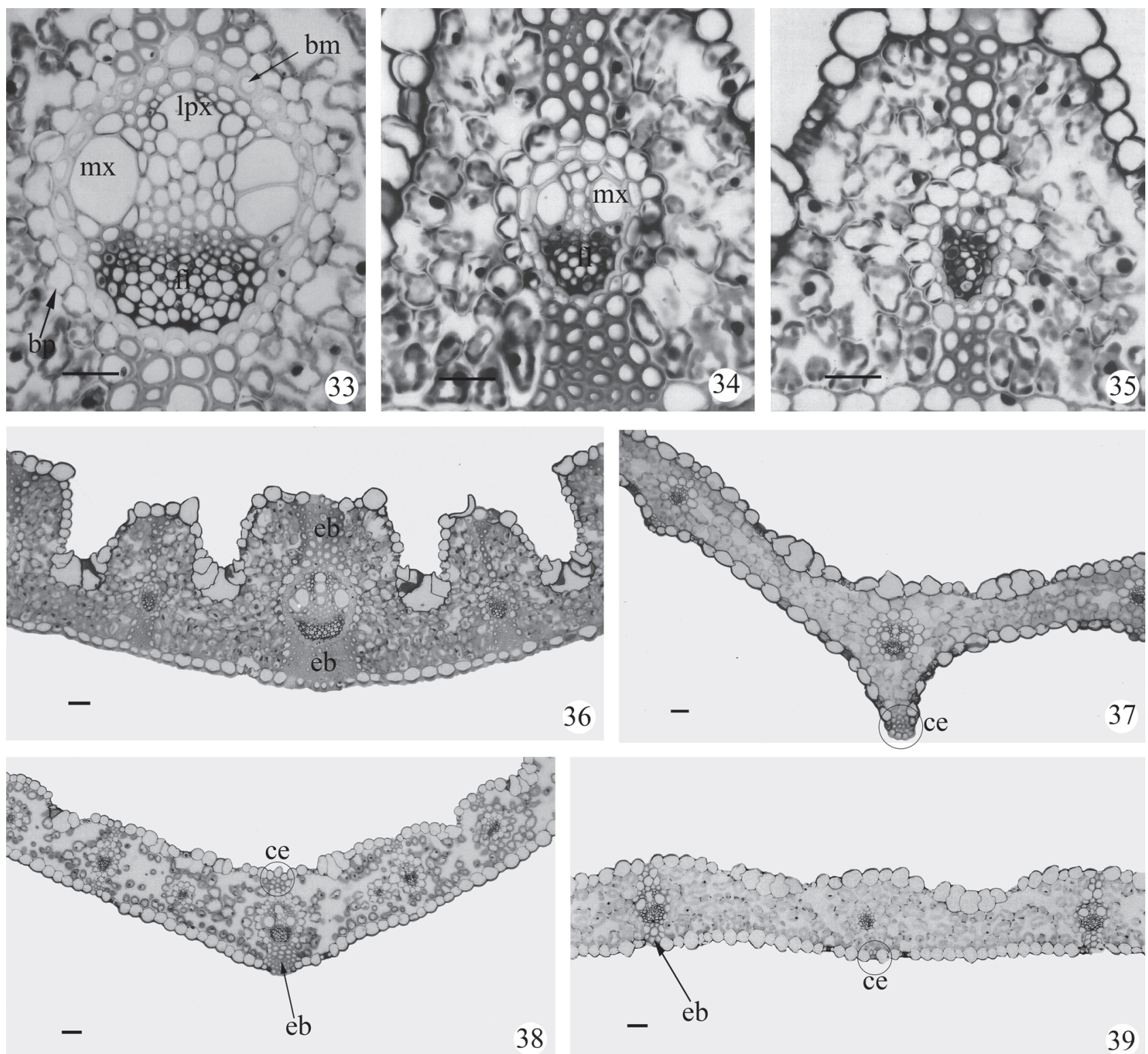

Figuras 33-39. Secção transversal da lâmina foliar. 33-36. Briza subaristata Lam. var. subaristata. 33. feixe vascular de primeira ordem, duas bainhas perivasculares. 34. feixe vascular de segunda ordem. 35. feixe vascular de terceira ordem. 36. feixe vascular mediano e feixes de terceira ordem com extensão de bainha na face abaxial e cordão alongado na face adaxial. 37. Briza minor L., região do feixe vascular mediano com quilha, cordão arredondado de esclerênquima na face abaxial; 38. Briza media L., mesofilo frouxo, feixe vascular mediano com cordão arredondado de esclerênquima na face adaxial e extensão de bainha esclerenquimática na face abaxial. 39. Briza maxima L., feixe vascular de terceira ordem com cordão de esclerênquima arredondado apenas na face abaxial. Barra $=30 \mu \mathrm{m} ; \mathrm{bp}=$ bainha parenquimática; $\mathrm{bm}=$ bainha mestomática; $\mathrm{ce}=$ cordão de esclerênquima; $\mathrm{eb}=$ extensão de bainha, $\mathrm{fl}=\mathrm{floema} ; \mathrm{mx}=\mathrm{metaxilema;}$ lpx = lacuna de protoxilema. 


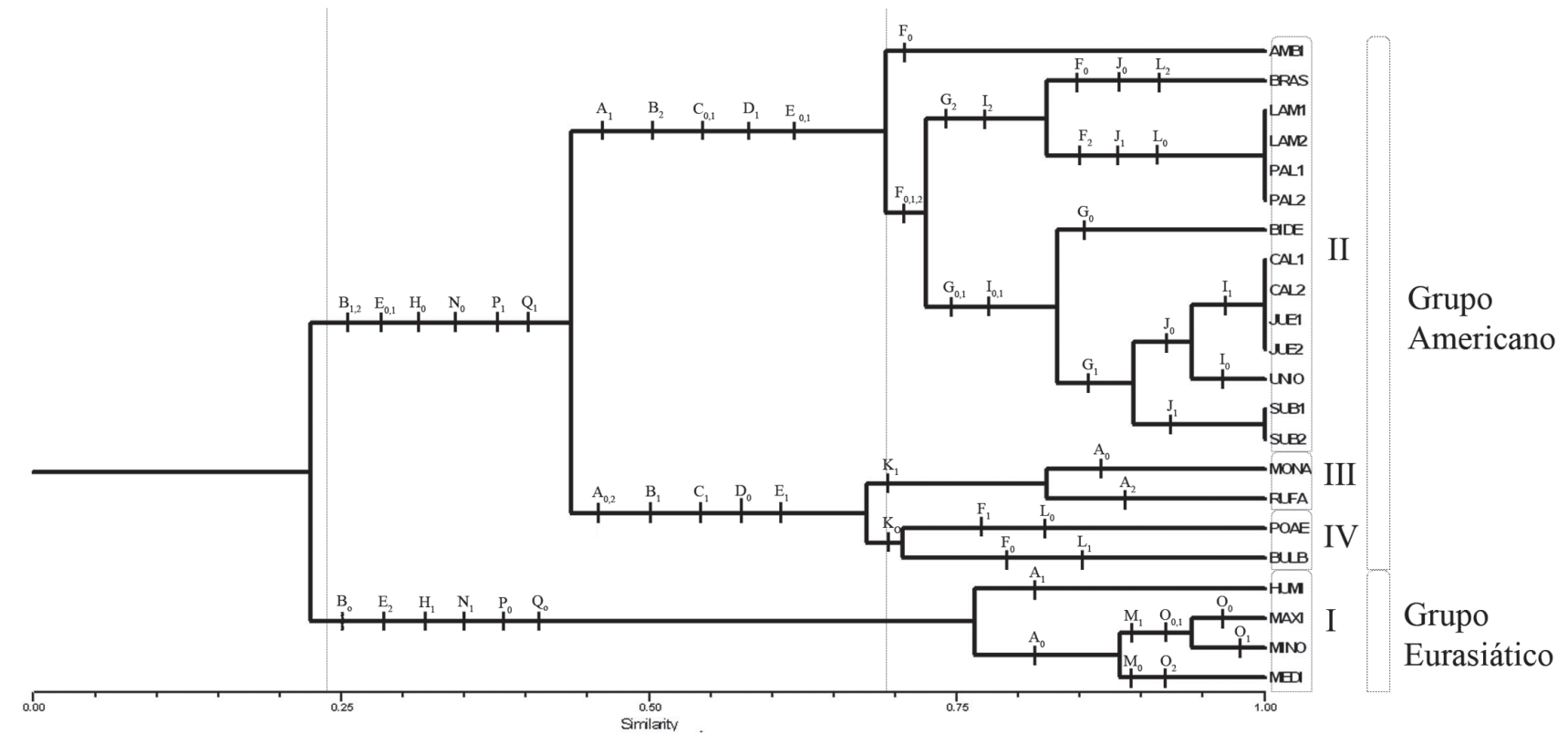

Figura 40. Fenograma de agrupamento através de UPGMA para 21 táxons de Briza L. e um de Erianthecium Parodi, baseado em 17 caracteres da face abaxial da epiderme e secção transversal da lâmina foliar. I, II, III, IV: grupos estáveis. Os acrônimos dos táxons estão especificados na Tab. 1. As letras e números correspondem aos caracteres e estados da Tab. 4.

taxometria das proteínas da semente, com Savchenko et al. (1998), com base em estudos de distribuição de fitoecdisteróides, e com Essi et al. (2008), que utilizaram dados moleculares, ressaltando não haver suporte para a aceitação de Briza s.l. Essi et al. (2008) separaram as espécies eurasiáticas de Briza (grupo I no presente trabalho) das americanas, considerando como pertencentes à Briza apenas as eurasiáticas, enquanto as americanas como pertencentes ao gênero Chascolytrum, incluindo Erianthecium bulbosum, o que foi confirmado no presente estudo. Esta espécie apresenta anatomia foliar igual às demais espécies americanas do Complexo, exceto pela presença de tricomas longos nas duas faces da epiderme. Por outro lado, verifica-se que, no grupo das espécies americanas, formam-se três subgrupos estáveis com $69 \%$ de similaridade (Fig. 40), contrastando com os resultados de Essi et al. (2008), onde não se formaram grupos definidos, devido à existência de importantes politomias nos cladogramas obtidos. Porém, os três subgrupos das espécies americanas não correspondem a nenhuma proposta anterior de organização das mesmas em categorias taxonômicas, genéricas ou infragenéricas. Por exemplo, o grupo II é formado por representantes das seções Poidium e Chascolytrum anteriormente aceitas para Briza por Longhi-Wagner (1987).

Briza lamarckiana e $B$. aff. lamarckiana não apresentam distinção quanto à anatomia foliar, não apoiando nenhuma proposição de categoria infra-específica que possa ser feita com base nesse caráter. Esses dois táxons são morfologicamente bem distintos de B. paleapilifera e $B$. aff. paleapilifera, porém não foi possível distinguí-los com base em caracteres da anatomia foliar, como evidenciado no fenograma (Fig. 40).
Por sua vez, Briza paleapilifera típica, proveniente da Argentina, e B. aff. paleapilifera, da Bolívia, foram consideradas espécies distintas por Essi (2007), com base em dados moleculares e morfológicos (tipo e localização de tricomas da espigueta). No presente trabalho, as duas espécies não apresentaram características anatômicas que justifiquem essa separação.

Briza subaristata exibe grande variação morfológica, principalmente relacionada às dimensões da espigueta, caráter utilizado por alguns autores para separar duas variedades (Rosengurtt et al. 1968), B. subaristata var. interrupta, com lemas de até $3 \mathrm{~mm}$ de comprimento, e B. subaristata var. subaristata, com lemas mais longos. Não foram encontrados caracteres na anatomia foliar que apóiem a aceitação dessas duas variedades, o que reforça a sinonimização proposta por Essi (2007).

Briza juergensii e $B$. aff. juergensii não se distinguem quanto à anatomia foliar, em contraposição às diferenças morfológicas relacionadas à espigueta referidas por LonghiWagner (1987) e Matthei (1975), ou seja, lemas mais largos, na primeira espécie. Embora Essi (2007), com base em dados morfológicos, tenha proposto $B$. aff. juergensii como uma nova variedade, os caracteres anatômicos aqui analisados não respaldam essa separação. Briza juergensii e $B$. aff. juergensii também não se separam de $B$. calotheca pela anatomia foliar. Estes táxons são bem semelhantes morfologicamente, ambos pertencendo à seção ou subgênero Poidium, como aceito por alguns autores. A sua distinção é feita apenas pela presença de tricomas nas páleas e nos lemas de $B$. juergensii $\mathrm{e} B$. aff. juergensii, ausentes em $B$. calotheca.

Longhi-Wagner (1987) relatou que indivíduos de Briza calotheca, provenientes de ambientes úmidos ou alagados, 
exibem maior porte e lâminas foliares mais largas e mais rígidas do que os de ambientes secos, o que também foi observado nas coletas para o presente estudo. Entretanto, os indivíduos de $B$. calotheca coletados em banhado e em campo seco aqui analisados, não mostram adaptações anatômicas foliares relacionadas a esses ambientes contrastantes.

Ainda considerando o grupo II (Fig. 41), convém salientar que Briza brasiliensis, excluída por Matthei (1975) do Complexo Briza, mostra várias semelhanças anatômicas com as espécies do Complexo, concordando com o seu posicionamento junto às demais espécies americanas, como proposto por Essi et al. (2008). Da mesma forma, $B$. bidentata, considerada como pertencente ao gênero Rhombolytrum por Matthei (1975), compartilha várias características com as demais espécies do grupo II.

O grupo IV é formado apenas por duas espécies morfologicamente distintas e aceitas como gêneros diferentes, Briza poaemorpha e Erianthecium bulbosum por Longhi-Wagner (1987). Esta última é facilmente distinta vegetativamente, de qualquer outra espécie do Complexo Briza, pelo engrossamento característico nos entrenós basais do colmo (Longhi-Wagner 1987). Apesar disso, Essi et al. (2008) incluíram E. bulbosum no gênero Chascolytrum, juntamente com as demais espécies americanas do Complexo. Quanto à anatomia foliar aqui discutida, as duas espécies do grupo IV assemelham-se, e separam-se apenas pela presença de tricomas longos nas duas faces da epiderme de E. bulbosum, corroborando a proposta de Essi et al. (2008).

Os resultados obtidos permitem distinguir as espécies eurasiáticas das americanas. Porém, quanto ao grupo das americanas, os três agrupamentos obtidos não correspondem a nenhuma proposta anterior de organização dos mesmos em categorias taxonômicas, genéricas ou infragenéricas. Reforçam a aceitação de Briza s. str., incluindo apenas as espécies eurasiáticas. Por sua vez, os resultados sugerem a inclusão, no grupo das americanas, de Erianthecium bulbosum bem como de B. brasiliensis e B. bidentata, as duas últimas excluídas por Matthei (1975) do Complexo.

Entre as características da epiderme analisadas, as mais relevantes para a distinção entre as espécies eurasiáticas e americanas são a ausência de células suberosas na face abaxial da epiderme e a forma oblonga dos corpos silicosos, nas primeiras, sendo suborbiculares ou bilobados/polilobados nas demais espécies. Com relação às características anatômicas da lâmina foliar em secção transversal, destacam-se, na delimitação dos dois grupos, menor quantidade de esclerênquima associado aos feixes vasculares, os cordões de esclerênquima do bordo da lâmina com menos de dez fibras, a presença de quilha na lâmina, e o mesofilo frouxo com grandes espaços intercelulares, nas espécies eurasiáticas.

Quanto à aceitação de táxons infra-específicos para abrigar as diferenças morfológicas mencionadas por Matthei (1975), Longhi-Wagner (1987) e Essi (2007) para os morfotipos de Briza calotheca, B. juergensii, B. lamarckiana, $B$. paleapilifera e $B$. subaristata, a anatomia foliar destes não apresentou variação que sustente a aceitação de categorias infra-específicas.

\section{Agradecimentos}

Ao Conselho Nacional de Desenvolvimento Cientifico e Tecnológico $(\mathrm{CNPq})$, pela bolsa de mestrado concedida à Carla M.G. de Pelegrin e pela bolsa de Produtividade em Pesquisa concedida a Hilda M. Longhi-Wagner; à Camila C. Both, pelo auxílio nas interpretações estatísticas; aos Professores Jorge E.A. Mariath, Tatiana de S. Teixeira-Chies e Sílvia R. Machado, pela análise da dissertação e valiosas sugestões.

\section{Referências bibliográficas}

Acedo, C. \& Llamas, F. 2001. Variation of micromorphological characters of lemma and palea in genus Bromus (Poaceae). Annales Botanici Fennici 38: 1-14.

Aiken, S.G. \& Lefkovitch, L.P. 1983. The taxonomic value of using epidermal characteristics in the Canadian rough fescue complex (Festuca altaica, F. campestris, F. hallii, F. scabrella). Canadian Journal of Botany 62: 1864-1870.

Aiken, S.G.; Darbyshire, S.J. \& Lefkovitch, L.P. 1984. Restricted taxonomic value of leaf sections in Canadian narrow-leaved Festuca (Poaceae). Canadian Journal of Botany 63: 995-1005.

Alquini, Y.; Bona, C.; Boeger, M.R.T.; Costa, C.G.; Barros, C.F. 2006. Epiderme. Pp. 87-107. In: B. Appezzato da Glória; S.M. CarmelloGuerreiro (eds.). Anatomia vegetal. Viçosa, Editora da Universidade Federal de Viçosa.

Alvarez, J.M.; Rocha, J.F. \& Machado, S.R. 2005. Estrutura foliar de Loudetiopsis chrysothrix (Nees) Conert e Tristachya leiostachya Nees (Poaceae). Revista Brasileira de Botânica 28: 23-37.

Badoux, S. 1971. Sur I'anatomie de la feuille de Festuca arundinacea Schrer., Festuca pratensis Huds., Lolium multiflorum Lam. et leurs hybrides. Bulletin de la Societe Vaudoise des Sciences Naturelles 71: 335 15-22.

Bayón, N.D. 1998. Cladistic analysis of the Briza complex (Poaceae, Poeae). Cladistics 14: 287-296.

Brown, W.V. 1958. Leaf anatomy in grass systematics. Botanical Gazette 119: 170-178.

Brown, W.V. 1975. Variations in anatomy, associations, and origins of Kranz tissue. American Journal of Botany 62: 395-402.

Cai, L.B.; Zhang, T.L. \& Hsaio, A.I. 2003. The circumscription and concept of Hordeum (Poaceae) based on some leaf epidermal characteristics. Israel Journal of Plant Sciences 51: 315-320.

Carolin, R.C.; Jacobs, W.L. \& Vesk, M. 1973. The structure of the cells of the mesophyll and parenchymatous bundle sheath of the Gramineae. Botanical Journal of Linnaean Society 66: 259-275.

Church, G.L. 1949. A cytotaxonomic study of Glyceria and Puccinellia. American Journal of Botany 36: 115-165.

Clayton, W.D. \& Renvoize, S.A. 1986. Genera graminum: grasses of the world. London, Her majesty's Stationery office.

Cutter, E.G. 1987. Anatomia Vegetal: parte II. Orgãos: experimentos e interpretação. São Paulo, Roca.

Decker, H.F. 1964. An anatomic-systematic study of the classical tribe Festucaceae (Gramineae). American Journal of Botany 51: 453-463.

Duval-Jouve, M.J. 1875. Histotaxie des feuilles de graminées. Annales des Sciences Natureles Series Botanique 1: 227-346.

Ellis, R.P. 1976. A procedure for standardizing comparative leaf anatomy in the Poaceae. I. The leaf-blade as viewed in transverse section. Bothalia 12: 65-109.

Ellis, R.P. 1979. A procedure for standardizing comparative leaf anatomy in the Poaceae II: the epidermis as seen in surface view. Bothalia 12: 641-671.

Ellis, R.P. 1987. A review of comparative leaf blade anatomy in the systematics of the Poaceae: the past twenty-five years. Pp. 3-10. In: T.R. Soderstrom; K.W. Hilu; C.S. Campbell \& M.E. Barkworth (eds.). Grass Systematics and Evolution. Washington, Smithsonian Institution Press. 
Escalona, F.D. 1991. Leaf anatomy of fourteen species of Calamagrostis section Deyeuxia, subsection Stylagrostis (Poaceae: Pooideae) from the Andes of South America. Phytologia 71: 187-204.

Essi, L. 2007. Análise filogenética e taxonômica do Complexo Briza (Poaceae - Poeae). Tese de Doutorado em Botânica, Universidade Federal do Rio Grande do Sul, Porto Alegre (não publicada).

Essi, L.; Longhi-Wagner, H.M. \& Souza-Chies, T.T. 2008. Phylogenetic analysis of the Briza Complex (Poaceae). Molecular Phylogenetics and Evolution 47: 1018-1029.

Fahn, A. \& Cutler, D.F. 1992. Xerophytes. Enciclopedia of plant taxonomy. Berlin, Gebruder Borntraeger.

Feder, N. \& O'Brien, T.P. 1968. Plant microtechnique: some principles and new methods. American Journal of Botany 55: 123-142.

Finot, V.L.; Baeza, C.M. \& Matthei, O. 2006. Micromorfología de la epidermis de la lemma de Trisetum y géneros afines (Poaceae, Pooideae). Darwiniana 44: 32-57.

Fisher, B.S. 1939. A contribution to the leaf anatomy of Natal grasses. Series I: Chloris Sw. and Eusthachys Desv. Annals of the Natal Museum 9: 245- 267.

Gerrits, P.O. \& Smid, L. 1983. A new, less toxic polymerization system for the embedding of soft tissues in glycol metacrylate and subsequent preparing of serial sections. Journal of Microscopy 132: $81-85$

GPWG (Grass Phylogeny Working Group). 2001. Phylogeny and subfamilial classification of the grasses (Poaceae). Annals of the Missouri Botanical Garden 88: 373-457.

Guevara, L.I. \& Ramia, M. 2007. Anatomía foliar de Panicum 1., sección Parvifolia (Poaceae, Paniceae) en Venezuela. Rodriguésia 58: 073-083.

Holmgren, P.K. \& Holmgren, N.H. 1998. Index Herbariorum on the Internet. Disponível em http://sciweb.nybg.org./science2/ IndexHerbariorum.asp (Acesso em 13/11/2007).

Johansen, D.A. 1940. Plant Microtechnique. New York, Mac GrawHill Book Company.

Kesler, T.R.; Anderson, L.C. \& Hermann, S.M. 2003. A taxonomic reevaluation of Aristida stricta (Poaceae) using anatomy and morphology. Southeastern Naturalist 2: 1-10.

Kharazian, N. 2007. The taxonomy and variation of leaf anatomical characters in the genus Aegilops L. (Poaceae) in Iran. Turkish Journal of Botany 31: 1-9.

King, G.J. 1986. A taxometric analysis of seed proteins in the genus Briza s.l. (Poaceae). Plant Systematic and Evolution 151: 163-174.

Lohauss, K. 1905. Der anatomische Bau der Laubblätter de Festucaceen und dessen Bedeutung für die Systematik. Bibliotheca Botanica 13: $1-114$

Longhi-Wagner, H.M. 1987. Gramineae: Tribo Poeae. Flora Ilustrada do Rio Grande do Sul. Boletim do Instituto de Biociências 41: 1-191.

López, J. \& Devesa, J.A. 1991. Contribución al conocimiento de la anatomía foliar de las Aveneae (Poaceae, Pooideae) del centrooeste de España. Anales del Jardim Botánico de Madrid 48: 171-187.

Ma, H.Y.; Peng, H. \& Li, D.Z. 2005. Taxonomic significance of leaf anatomy of Aniselytrum (Poaceae) as an evidence to support its generic validity against Calamagrostis s.l. Journal of Plant Research 118: 401-414.

Madella, M.; Alexandre, A. \& Ball, T. 2005. International code for phytolith nomenclature 1.0. Annals of Botany 96: 253-260.

Matthei, O. 1975. Der Briza-Komplex in Südamerika: Briza, Calotheca, Chascolytrum, Poidium (Gramineae) - eine revision. Willdenowia 8: $1-168$.

McDowell, E.M. \& Trump, B. 1976. Histological fixatives for diagnostic light and electron microscopy. Archives of Pathology \& Laboratory Medicine 100: 405-414.

Metcalfe, C.R. 1960. Anatomy of the monocotyledons. 1. Gramineae. Oxford, Clarendon Press.

Nicora, E.G. \& Rúgolo de Agrasar, Z.E. 1981. Los géneros sudamericanos afines a Briza L. (Gramineae). Darwiniana 23: 279-309.
Palmer, P.G. \& Tucker, A.E. 1981. A scanning electron microscopy survey of the epidermis of East African grasses I. Washington, Smihsonian Institution Press.

Parodi, L.R. 1920. Notas sobre las especies de Briza de la Flora Argentina. Revista de la Facultad de Agronomía y Veterinária de la Universidad de Buenos Aires 3: 113-137.

Pillar, V.P. 1999. How sharp are classifications. Ecology 80: 2508-2516.

Pillar, V.P. 2001. MULTIV: Multivariate Exploratory Analysis, Randomization Testing and Bootstrap Resampling. Software (free distribution version MULTIV Minor). Disponível em http://ecoqua.ecologia.ufrgs.br (Acesso em 25/07/2007).

Piperno, D.R. \& Pearsall, D.M. 1998. The silica bodies of tropical American grasses: morphology, taxonomy, and implications for grass systematics and fossil phytolith identification. Smithsonian Contributions to Botany 85: 1-40.

Prat, H. 1936. La systematique des Graminées. Annales des Sciences Naturales Series Botanique 10: 165-258.

Prychid, C.J.; Rudall, P.J. \& Gregory, M. 2004. Systematics and biology of silica bodies in monocotyledons. Botanical Review 69: 377-440.

Reimer, E. \& Cota-Sánchez, J.H. 2007. A SEM survey of the leaf anatomy epidermis in Danthonioid grasses (PoaceaeDanthonioideae). Systematic Botany 32: 60-70.

Rohlf, F.J. 2000. NTSYS 2.1: Numerical Taxonomic and Multivariate Analysis System. Exeter Software.

Rosengurtt, B.; Arrillaga de Maffei, B.R. \& Izaguirre de Artucio, P. 1968. Sinopsis de Briza (Gramineae) del Uruguay y notas taxonómicas sobre otras especies de este género. Boletin de la Facultad de Agronomía de la Universidad de Montevideo 105: $1-35$.

Rosengurtt, B. \& Arrillaga de Maffei, B.R. 1979. Lombardochloa, nuevo género de Gramineae. Anales de la Facultad de Química de Montevideo 9: 255-268.

Sánchez, M.G. \& Koch, S.D. 1998. Estúdio anatomico comparativo de la lámina foliar de Eragrostis (Poaceae: Chloridoideae) de México. Acta Botánica Mexicana 43: 33-56.

Sass, J.E. 1951. Botanical microtechnique. New York, The lowa State College Press.

Savchenko, T.; Whiting, P.; Šik, V.; Underwood, E.; Sarker, S.D. \& Dinan, L. 1998. Distribution and identities of phytoecdysteroids in the genus Briza (Gramineae). Biochemical Systematic and Ecology 26: 781-791.

Schwendener, V.S. 1890. Die Mestomscheiden der Gramineenblätter. Sitzungsberichte Akademie Berlin 405-426.

Silva, L.M. \& Alquini, Y. 2003. Anatomia comparativa de folhas e caules de Axonopus scoparius (Flügge) Kuhlm. e Axonopus fissifolius (Raddi) Kuhlm. (Poaceae). Revista Brasileira de Botânica 26: 185-192.

Soderstrom, T.R. 1967. Taxonomic study of subgenus Podosemum and section Epicampes of Muhlenbergia (Gramineae). Contributions of the U.S. National Herbarium 34: 75-189.

Torres, I.H. \& Engleman, E.M. 1995. Anatomia de la lámina foliar del género Trisetum (Gramineae: Pooideae) en México. Acta Botánica Mexicana 31: 39-50.

Vieira, R.C.; Gomes, V.R.C.; Sarahyba, D.M.S. \& Arruda, R.C.O. 2002. Leaf anatomy of three herbaceous bamboo species. Brazilian Journal of Biology 62: 907-922.

Watson, L. \& Johnston, C.R. 1978. Taxonomic variation in stomatal insertion among grasses leaves. Australian Journal of Botany 26: $235-238$.

Watson, L. \& Dallwitz, M.J. 1992. The grass genera of the world: descriptions, illustrations, identification, and information retrieval: including synonyms, morphology, anatomy, physiology, photochemistry, cytology, classification, pathogens, world and local distribution, and reference. Disponível em http://deltaintkey.com (Acesso em 12/08/2007).

Wenzel, C.L.; Chandler, P.M.; Cunningham, R.B. \& Passioura, J.B. 1997. Characterization of leaf epidermis of barley (Hordeum vulgare L. Himalaya). Annals of Botany 79: 41-46. 